Manuscript in press at Development \& Psychopathology

Submitted 8/17/2020

Accepted 11/08/2020 


\title{
Prospective Longitudinal Associations between Harsh Parenting and Corticolimbic
}

\author{
Function during Adolescence
}

\author{
Arianna M. Gard ${ }^{1}$, Tyler C. Hein ${ }^{1,2}$, Colter Mitchell ${ }^{3}$, Jeanne Brooks-Gunn ${ }^{4,5}$, Sarah S. \\ McLanahan $^{6-8}$, Christopher S. Monk ${ }^{1,3,9}$, \& Luke W. Hyde ${ }^{1,3,9}$ \\ ${ }^{1}$ Department of Psychology, University of Michigan, Ann Arbor, MI, USA \\ ${ }^{2}$ Serious Mental Illness Treatment Resource Evaluation Center, Office of Mental Health and \\ Suicide Prevention, Department of Veterans Affairs, Ann Arbor, MI, USA \\ ${ }^{3}$ Survey Research Center of the Institute for Social Research, University of Michigan, Ann Arbor, \\ MI, USA \\ ${ }^{4}$ Teachers College and the College of Physicians and Surgeons and ${ }^{5}$ Columbia Population \\ Research Center, Columbia University, New York, NY, USA \\ ${ }^{6}$ Department of Sociology and Public Affairs, ${ }^{7}$ Center for Research on Child Wellbeing, \& \\ ${ }^{8}$ Office of Population Research, Princeton University, Princeton, NJ, USA \\ ${ }^{9}$ Center for Human Growth and Development, University of Michigan, Ann Arbor, MI, USA
}

\section{Acknowledgments}

This research was supported in part by grants from the National Institutes of Health (T32HD00701936, T32-HD007339, R01-HD036916, R01-HD39135, R01-HD40421, and R01MH103761), the National Science Foundation (NSF 1519686), and a consortium of private foundations that supported the Fragile Families and Child Wellbeing Study. We are grateful for the work of the staff of the Fragile Families and Child Wellbeing Study and the Study of Adolescent Neurodevelopment for their many years of service. We thank our study families for sharing their lives with us and making this research possible.

Corresponding Author

Luke W. Hyde

University of Michigan Department of Psychology

530 Church Street

Ann Arbor, MI 48109

lukehyde@umich.edu 


\begin{abstract}
Childhood adversity is thought to undermine youth socioemotional development via altered neural function within regions that support emotion processing. These effects are hypothesized to be developmentally specific, with adversity in early childhood sculpting subcortical structures (e.g., amygdala) and adversity during adolescence impacting laterdeveloping structures (e.g., prefrontal cortex; PFC). However, little work has tested these theories directly in humans. Using prospectively-collected longitudinal data from the Fragile Families and Child Wellbeing Study $(N=4,144)$ and neuroimaging data from a subsample of families recruited in adolescence $(N=162)$, the current study investigated the trajectory of harsh parenting across childhood (i.e., ages 3 to 9) and how initial levels versus changes in harsh parenting across childhood were associated with corticolimbic activation and connectivity during socioemotional processing. Harsh parenting in early childhood (indexed by the intercept term from a linear growth curve model) was associated with less amygdala, but not PFC, reactivity to angry facial expressions. In contrast, change in harsh parenting across childhood (indexed by the slope term) was associated with less PFC, but not amygdala, activation to angry faces. Increases in, but not initial levels of, harsh parenting were also associated with stronger positive amygdalaPFC connectivity during angry face processing.
\end{abstract}

Keywords: harsh parenting, amygdala, corticolimbic, socioemotional, adversity 


\section{Prospective Longitudinal Associations between Harsh Parenting and Corticolimbic Function during Adolescence}

Exposure to childhood adversity is associated with maladaptive developmental outcomes, including the emergence and persistence of psychopathology (Green et al., 2010; Lupien et al., 2009). Research is beginning to show that adversity may become biologically-embedded by affecting brain development via stress-related processes (McEwen, 2012), with recent emphasis on the effects of adversity within the caregiving context (Callaghan \& Tottenham, 2016). However, much of this work has focused on extreme features of caregiving (e.g., childhood maltreatment, early institutionalization), rather than how more common forms of adversity within the parent-child relationship, such as harsh parenting, may be related to brain function. Moreover, although prominent theories (Lupien et al., 2009; Tottenham, 2015) have emphasized that different brain regions mature at different rates and, thus, may be more or less sensitive to adversity during different developmental periods, little work in humans has tested how the timing of adversity modulates its effects on brain function. Thus, more research is needed to examine how and when harsh parenting affects later brain function, particularly within neural regions key to stress responses and socioemotional functioning.

\section{Harsh Parenting across Childhood}

Harsh parenting is characterized by high intrusion, coerciveness, and physical or verbal aggression (Bugental \& Grusec, 2006; Darling \& Steinberg, 1993; Tamis-LeMonda et al., 2008). Overly harsh behaviors create an environment of inconsistency and unpredictability that results in pronounced child behavioral problems and concomitant changes in biological stress responses (Bugental \& Grusec, 2006; Loman \& Gunnar, 2010). Parenting behaviors during early childhood are thought to be particularly important for youth socioemotional development (Ainsworth, 
1979; Bowlby, 1982; Landry et al., 2008; Maccoby \& Martin, 1983; Patterson, 1982; Shaw \& Bell, 1993). For example, hostile and rejecting parenting behaviors during toddlerhood, when children become increasingly mobile and autonomous, facilitate coercive family processes that translate into later youth conduct problems (Patterson, 1982; Shaw et al., 2003; Shaw \& Bell, 1993). Although harsh parenting behaviors and parent-child conflict tend to be elevated during toddlerhood and decrease thereafter (Collins et al., 2005; Dallaire \& Weinraub, 2005; Trentacosta et al., 2011), most developmental work on parenting has examined parenting within shorter developmental periods, such as infancy (Dallaire \& Weinraub, 2005) or adolescence (Forehand \& Jones, 2002). Given the substantial individual (e.g., development of self-regulation) and social (e.g., entering school, forming peer relationships) changes that occur as youth move from early to late childhood (Blair \& Diamond, 2008; Morrison et al., 2010), more research is needed to describe how harsh parenting behaviors change across childhood.

\section{Neural Structures within the Corticolimbic System}

Neural structures within the corticolimbic system, including the amygdala and medial regions of the prefrontal cortex (PFC/mPFC), have been the focus of much of the research linking childhood adversity to brain development (Callaghan \& Tottenham, 2016; Gee, 2016; McLaughlin, Sheridan, \& Lambert, 2014). Given its critical role in emotion processing, salience detection, and fear learning (LeDoux, 2000), the amygdala forms the "hub" of the corticolimbic system (Benes, 2010; Hariri, 2015). Neurons within the amygdala integrate information about the external environment from sensory cortices with contextual information from the hippocampus, sending efferent projections to other subcortical (e.g., hypothalamus) and cortical (e.g., PFC) regions to stimulate behavioral responses (e.g., activation of physiological stress responses, attention allocation) (LeDoux, 2000; Whalen \& Phelps, 2009). Regions of the medial 
PFC (mPFC) and anterior cingulate cortex (ACC) support emotion regulation by integrating affective valuations from the amygdala with inputs from other neural regions (e.g., brainstem, thalamus) (Etkin et al., 2011; Fuster, 2001; Ochsner et al., 2012; Quirk et al., 2006). In fMRI tasks that present emotional facial expressions, the mPFC (e.g., middle and medial frontal gyri), ACC, and amygdala are more active when participants view expressions of interpersonal distress (i.e., fear) and threat (i.e., anger) than neutral faces (Ekman \& Friesen, 1976; Fusar-Poli et al., 2009; Oatley \& Johnson-Laird, 1987). Individual differences in amygdala, mPFC, and ACC reactivity to fearful and angry facial expressions have been associated with dysregulated cortisol signaling (Henckens et al., 2016), internalizing (Etkin, Egner, \& Kalisch, 2011; Groenewold, Opmeer, de Jonge, Aleman, \& Costafreda, 2013; Kim et al., 2011; Monk, 2008), and externalizing behaviors (Coccaro et al., 2007; Hyde et al., 2013; Marsh \& Blair, 2008; Yang \& Raine, 2009) - all outcomes that have also been linked to adversity in childhood (Green et al., 2010; Loman \& Gunnar, 2010).

Dense structural (Bzdok et al., 2013; Goetschius et al., 2019) and functional (Motzkin et al., 2015; Roy et al., 2009) connectivity between the amygdala, regions of the mPFC, and the ACC suggests that an examination of activation within these regions can be complemented by exploring their connectivity (Menon, 2011). Indeed, amygdala-PFC connectivity has been associated with multiple forms of psychopathology that are marked by deficits in emotion processing, cross-sectionally (Hyde, Shaw, \& Hariri, 2013; Kim et al., 2011; Price \& Drevets, 2010) and longitudinally (Gard et al., 2018; Waller et al., 2018).

\section{Adversity Effects on Corticolimbic System Function}

A rich literature has linked greater childhood adversity with both greater (Gianaros et al., 2008; Jedd et al., 2015; Maheu et al., 2010; McCrory et al., 2011; Pozzi et al., 2019; Suzuki et 
al., 2014; Tottenham et al., 2011) and less (Gard et al., 2017; Holz et al., 2017; Javanbakht et al., 2015; Taylor et al., 2006) amygdala reactivity to fearful and angry facial expressions. Emotional neglect and childhood trauma have also been associated with greater lateral PFC activation during emotion regulation (Colich et al., 2017; Marusak et al., 2015), and less mPFC reactivity to angry and fearful facial expressions (van Harmelen et al., 2014). More research is needed to address these directional inconsistencies, which may emerge from different operationalizations of adversity and/or that some studies combine angry and fearful facial expressions into one “threat" condition or examine only one facial expression (i.e., angry or fear). For example, most of the research linking adversity to threat-related amygdala function (reviewed in Hein \& Monk, 2017) has focused on the neural effects of childhood maltreatment and reported positive associations (for examples of structural MRI studies that have examined normative parenting behaviors, see Whittle et al., 2008, 2014, 2016, 2017). Although far fewer task-based fMRI studies have examined more common forms of adversity (e.g., harsh parenting), those that have (Gard et al., 2017; Holz et al., 2017) reported negative associations with threat-related amygdala reactivity (although see Pozzi et al., [2019]). For examinations of prefrontal function, inconsistencies in previous work may also stem from region-of-interest approaches that do not account for functional heterogeneity within the PFC (e.g., dorsal versus ventral regions).

Comparatively few studies have examined the effects of adversity on corticolimbic connectivity during socioemotional processing. However, as in studies of amygdala activation, the pattern of results appears to diverge depending on the operationalization of adversity. Childhood maltreatment and previous institutionalization have been associated with stronger amygdala-mPFC connectivity during fear processing (Gee, Gabard-Durnam, et al., 2013), angry and fear processing as one "threat condition" (Jedd et al., 2015), negative versus neutral images 
(Peverill et al., 2019), and while viewing several emotional facial expressions versus shapes (Miller et al., 2020; Pozzi et al., 2019). In contrast, lower family income has been associated with weaker amygdala-PFC connectivity during emotion regulation (Kim et al., 2013), and during fearful face processing (Javanbakht et al., 2015). Thus, more research is needed to examine the associations between adversity and corticolimbic connectivity, with greater attention to common aspects of childhood adversity (e.g., harsh parenting). Directional inconsistencies in the literature may also stem from reliance on relatively small samples recruited by convenience or based on narrow inclusion criteria (e.g., maltreated samples). More research is needed using larger population-based samples with a clear sampling frame that includes families with dimensional exposure to adversity.

\section{Environmental Effects on Corticolimbic Function: Consideration of Developmental Timing}

The developmental trajectories of the amygdala and the PFC suggest that there may be multiple windows of vulnerability during which these regions may be differentially sensitive to the effects of adversity. Structurally, the rate of volumetric growth in the amygdala is largest during the early postnatal years (Payne et al., 2010), increasing in volume by more than $100 \%$ during the first year of life (Gilmore et al., 2012). The PFC, however, continues to develop throughout childhood into adolescence and adulthood (Gogtay et al., 2004; Sowell et al., 2003). Prefrontal gray matter density has been shown to peak during the pre-pubertal stage (i.e., 10 - 12 years), followed by synaptic pruning and dendritic arborization (Andersen \& Teicher, 2008; Casey et al., 2008; Lenroot \& Giedd, 2006). Functionally, children exhibit greater amygdala reactivity to emotional facial expressions than adolescents and adults (Monk, 2008), and this trajectory is thought to underlie normative childhood fears (e.g., separation anxiety) that peak during childhood (Gee, 2016). During adolescence, as projections from prefrontal regions to 
other brain regions become more well-defined (Casey et al., 2008; Swartz et al., 2014), mPFC activation to emotional facial expressions increases (Blakemore, 2008). In a seminal paper by Gee and colleagues (2013), amygdala-mPFC connectivity during fear processing was shown to shift from positive during childhood to negative during adolescence. In this analysis, positive amygdala-mPFC connectivity reflected positively correlated amygdala and mPFC activation while children were looking at fearful facial stimuli; in adolescents and adults, the association between activity in these two regions became negative, thought to reflect less amygdala and greater mPFC activation (Gee, Humphreys, et al., 2013; Wu et al., 2016).

Although several recent reviews highlight the importance of developmental timing for adversity effects on corticolimbic function (Lupien et al., 2009; Tottenham, 2015), few studies have tested this hypothesis in humans (for reviews of the non-human animal literature, see Callaghan \& Tottenham, 2016; Debiec \& Sullivan, 2017). Using structural MRI, Pechtel and colleagues (2014) found that the severity of exposure to maltreatment at ages 10-11 was most strongly associated with amygdala volume. Similarly, Andersen et al. (2008) found that sexual abuse in early childhood was more strongly associated with subcortical volumes, whereas sexual abuse that occurred in late adolescence was more strongly associated with prefrontal volume. Beyond these structural studies, there is little work examining developmental timing using taskbased fMRI. In one exception, using prospectively-collected repeated measures of adversity across childhood, one study found that harsh parenting at age 2 was associated with less amygdala reactivity to fearful facial expressions at age 20, even after accounting for harsh parenting at age 12 (Gard et al., 2017); however, this paper did not examine PFC function or amygdala-PFC connectivity. Moreover, by measuring parenting behaviors at isolated time points, this strategy assumes that parenting can be parsed into discrete moments in time rather 
than the notion that parenting behaviors are a product of continuous reciprocal interactions within the changing context (Cicchetti \& Toth, 2009). It may be that an examination of initial levels (i.e., harsh parenting in early childhood) versus changes thereafter (i.e., the trajectory of harsh parenting across childhood) will reveal more complex effects of adversity on corticolimbic function during socioemotional processing. This explicit focus on evaluating the timing of harsh parenting effects on corticolimbic function builds on previous work in this sample that has examined the cumulative (i.e., across childhood) effects of threat- and deprivation-related experiences of adversity on amygdala-prefrontal white matter connectivity (Goetschius et al., 2020), amygdala reactivity during socioemotional processing (Hein, 2019), and network-level resting-state functional connectivity (Goetschius et al., In Press)

\section{The Present Study}

The current study sought to advance our understanding of how trajectories of maternal harshness across childhood impact corticolimbic function in adolescence. First, in a large, nationally-representative sample of children born in large US cities in 1998-2000 with an oversample for non-marital births (i.e., the Fragile Families and Child Wellbeing Study), we examined how parental harshness changed across childhood (i.e., from ages three to nine) using linear growth curve modeling. Second, we evaluated the effects of harsh parenting in early childhood versus changes in harsh parenting across childhood on corticolimbic function during adolescence. There were two components to our hypotheses: (1) predictions about the timing of harsh parenting effects on subcortical versus cortical regions, and (2) predictions about the direction of effects. Consistent with animal models (Callaghan \& Tottenham, 2016; Debiec \& Sullivan, 2017) and limited structural and functional longitudinal studies in human populations (Andersen et al., 2008; Gard et al., 2017; Pechtel et al., 2014), we hypothesized that harsh 
parenting in early childhood would be associated with amygdala function, whereas changes in harsh parenting across childhood would be associated with prefrontal function (particularly in within medial regions). Additionally, as amygdala-PFC connectivity is a function of activation in both regions, we hypothesized that both initial levels and changes in harsh parenting across childhood would be associated with corticolimbic connectivity. As the previous literature varies widely with respect to the direction of effects (e.g., due to operationalization of adversity, definition of PFC target regions), however, our directional hypotheses were more exploratory in nature. That is, we hypothesized that harsh parenting in early childhood would be related to either greater (Hein \& Monk, 2017) or less (Gard et al., 2017; Holz et al., 2017) threat-related amygdala reactivity, increases in harsh parenting across childhood would be related to either greater (Colich et al., 2017) or less (van Harmelen et al., 2014) threat-related PFC reactivity, and harsh parenting during early childhood and increases in harsh parenting across childhood would be associated with either weaker (Javanbakht et al., 2015) or stronger (Gee, Gabard-Durnam, et al., 2013) amygdala-mPFC connectivity during threat processing.

\section{Methods}

\section{Sample}

Participants were part of the Fragile Families and Child Wellbeing Study (FFCWS), a longitudinal cohort of 4,898 children ( $52.4 \%$ boys) children born in large U.S. cities between 1998 and 2000. The FFCWS oversampled for non-marital births $(\sim 3: 1)$, which resulted in substantial sociodemographic diversity in the sample (Reichman et al., 2001). At childbirth, mothers identified as Black Non-Hispanic $(\mathrm{N}=2,326,47.5 \%)$, White Non-Hispanic $(\mathrm{N}=1,030$, $21.1 \%)$, Hispanic $(\mathrm{N}=1,336,27.3 \%)$, or other $(\mathrm{N}=194,4.0 \%)$. Nearly $40 \%$ of the mothers reported less than a high school education at the birth interview, 25.3\% with a high school degree 
or equivalent, $24.3 \%$ some college or technical training, and $10.7 \%$ who earned a college degree or higher. Parents in the FFCWS were interviewed at the hospital shortly after the birth of the target child, and again (by phone or in-person) at ages 1, 3, 5, 9, and 15 years old. Retention of the baseline sample was generally high at each of the assessment periods ( $77 \%$ to $90 \%$ for mother or primary caregiver interviews, $62 \%$ to $72 \%$ for home visits) (for detailed information about cohort retention across waves, see https://fragilefamilies.princeton.edu).

At age 15, families from the Detroit, Toledo, and Chicago subsamples were asked to participate in the Study of Adolescent Neurodevelopment (SAND), a follow-up study to investigate the role of the environment on youth brain and behavioral development. Twohundred and thirty-seven adolescents aged 15 to 17 (52.3\% female) and their primary caregiver agreed to participate. Of the 237 families, teens self-identified as Black Non-Hispanic $(N=179$, $75.5 \%)$, Black Hispanic $(N=2,0.8 \%)$, White Non-Hispanic $(N=30,12.7 \%)$, of Hispanic or Latino origin $(N=10,4.2 \%)$, biracial $(N=13,5.5 \%)$, or other Non-Hispanic $(N=3,1.3 \%)$. Primary caregivers were biological mothers $(N=216,91.1 \%)$, biological fathers $(N=11,4.6 \%)$, adoptive parents $(N=4,1.7 \%)$, or other family members $(N=6,2.5 \%)$. Median annual family income was between $\$ 25,000$ to $\$ 29,999$, with some primary caregivers reporting annual incomes below $\$ 4,999$ (13\%) and others reporting annual incomes above $\$ 90,000(10.2 \%)$. Thus, the SAND sample is socioeconomically diverse, though primarily low-income, and comprised of mostly Black American children and their biological mothers.

\section{Procedure}

The current paper uses data from both the core FFCWS and the SAND. We used measures of maternal harsh parenting come from the core FFCWS telephone and in-person interviews at ages 3,5 , and 9. As the primary aim of this paper was to investigate whether initial 
levels and/or changes in parenting behaviors across childhood impacted youth corticolimbic function in adolescence, we limited our sample to families where the biological mother was the primary caregiver at the 3- , 5- , and 9-year assessments (i.e., to prevent artifacts introduced by changing informants across time); 216 out of 4,898 families were excluded. Detailed descriptions of the study protocols for each of the core FFCWS assessment periods can be found on the study website (https://fragilefamilies.princeton.edu).

SAND subsample. At age 15, primary caregivers and adolescents in the SAND study participated in a one-day protocol that included collection of self-report, interviewer, observational, and biological data. Parents provided written consent and adolescents provided verbal assent for their participation in the SAND protocol. Families were reimbursed for their participation. All assessments and measures were approved by the Institutional Review Board of the University of Michigan (IRB protocol \# HUM00074392).

\section{Measures}

Maternal harshness. Maternal harshness was measured as physical discipline using a sum of five mother-reported items from the physical aggression subscale of the Parent-Child Conflict Tactics Scale (Straus et al., 1998) at the 3-year (Mean[SD] = 1.23[1.01], $n=3,284)$, 5year $($ Mean[SD] $=1.10[.97], n=2,935)$, and 9-year $($ Mean[SD] $=.73[.85], n=3,083)$ assessments. Mothers were asked to rate how many times in the past year each disciplinary practice was used ("pinched him/her", "slapped him/her on the hand, arm, or leg”, "spanked him/her on the bottom with your bare hand", "hit child on the bottom with some hard object"), from 0 (never happened) to 6 (more than 20 items). The reliability of the harsh parenting items was low, though potentially adequate given the small pool of items (age 3: $\alpha=.61$; age 5: $\alpha=$ .60 ; age 9: $\alpha=.70$ ). This measure of harsh parenting has been used extensively in other 
publications from the FFCWS (e.g., Kim, Lee, Taylor, \& Guterman, 2014; Lee, Brooks-Gunn, McLanahan, Notterman, \& Garfinkel, 2013). Although we initially intended to include the psychological aggressions subscale of the Parent-Child Conflict Tactics Scale, the scale reliabilities were even lower than the physical aggressions subscale (e.g., at age 3: $\alpha=.55$ for psychological aggressions). Thus, we focused our analyses on physical discipline components of harsh parenting.

In sensitivity analyses, we evaluated whether our models were robust to inclusion of harsh parenting at age 15 (i.e., the time of neuroimaging assessment), which was measured by a mean of three parent-reported corporeal punishment items $($ Mean[SD] $=1.89[.63], n=159, \alpha=$ .59) from the Alabama Parenting Questionnaire (Frick, 1991). Harsh parenting at age 15, as measured by the physical aggression subscales of the Conflict Tactics Scale (Straus et al., 1998), could not be included as a time point in the linear growth curve models because only one item was collected in the age 15 wave of the FFCWS.

Covariates. Several covariates were included in the analyses, each of which have been shown to impact corticolimbic function (Alarcón et al., 2015; Kubota et al., 2012; Moore et al., 2012): (1) youth self-reported race and ethnicity at age 15, (2) youth gender (girl=1), and (3) youth self-reported pubertal development. Race/ethnicity was coded as one dummy code for the largest group in the SAND sample (Non-Hispanic Black [75.5\%] = 1). Pubertal development was measured at age 15 using youth report on the Pubertal Development Scale (Petersen et al., 1988), which includes two gender-specific items (e.g., for boys: voice changes; for girls: breast development), and three items for both genders (i.e., changes in height, skin, pubic hair). All items were rated on a 4 -point Likert scale $(1=$ process has not started, $4=$ seems completed $)$, except for the menarche question for girls, which was dichotomous $(1=$ not started, $4=$ started $)$. 
Total pubertal development score was calculated as a mean of the five items for each gender (girls: Mean $[\mathrm{SD}]=3.58[.46]$; boys: Mean $[\mathrm{SD}]=2.86[.50]$ ).

\section{Neuroimaging Data}

fMRI task. Participants completed an implicit emotion face processing task during continuous fMRI acquisition (see Figure 1). In this task, participants were asked to identify the gender of the actor by pressing their thumb for male or index finger for female (Hein et al., 2018). Faces from the NimStim set (Tottenham et al., 2009) were counterbalanced for gender and race (European American and African American). There were 100 pseudo-randomized trials, 20 trials each of the following emotions: fearful, happy, sad, neutral, and angry. Each trial consisted of a $500 \mathrm{~ms}$ fixation cross followed by a face presented for $250 \mathrm{~ms}$. A black screen then appeared for $1500 \mathrm{~ms}$, during which participants responded to the stimulus presentation, followed by a jittered inter-trial interval $(2000,4000$, or $6000 \mathrm{~ms})$. Total task time was 8.75 minutes. Accuracy and response times were collected using a non-metallic fiber optic transducer linked to a response box.

\section{[INSERT FIGURE 1 HERE]}

Data acquisition and pre-processing. MRI images were acquired using a GE Discovery MR750 3T scanner with an 8-channel head coil located at the UM Functional MRI Laboratory. High resolution T1-weighted gradient echo (SPGR) images were collected $(\mathrm{TR}=12 \mathrm{~ms}, \mathrm{TE}=$ $5 \mathrm{~ms}, \mathrm{TI}=500 \mathrm{~ms}$, flip angle $=15^{\circ}, \mathrm{FOV}=26 \mathrm{~cm} ;$ slice thickness $=1.4 \mathrm{~mm} ; 256 \times 192$ matrix; 110 slices) and used for pre-processing. Functional T2*-weighted BOLD images $(\mathrm{TR}=2000 \mathrm{~ms}$, $\mathrm{TE}=30 \mathrm{~ms}$, flip angle $=90^{\circ}, \mathrm{FOV}=22 \mathrm{~cm}$; slice thickness $=3 \mathrm{~mm} ; 64 \times 64$ matrix; 40 axial slices) were acquired using a reverse spiral sequence, which has been shown to improve signal recovery in frontal regions (Glover \& Law, 2001). Slices were prescribed parallel to the AC-PC 
line (same locations as structural scans). Slices were acquired contiguously, which optimized the effectiveness of the movement post-processing algorithms. Images were reconstructed off-line using processing steps to remove distortions caused by magnetic field inhomogeneity and other sources of misalignment to the structural data, which yields excellent coverage of subcortical areas of interest.

Anatomical images were homogeneity-corrected using SPM, then skull-stripped using the Brain Extraction Tool in FSL (version 5.0.7) (Jenkinson et al., 2012; Smith, 2002). Functional data were pre-processed in the following steps: removal of large temporal spikes in k-space data (> 2 std dev), field map correction and image reconstruction using custom code in MATLAB; and slice-timing correction using SPM12 (Wellcome Department of Cognitive Neurology, London, UK). To address head motion, functional images were realigned to the AC-PC plane in the mean image. Using SPM12, anatomical images were co-registered to the functional images. Functional images were normalized to the MNI Image space using parameters from the T1 images segmented into gray and white matter, cerebrospinal fluid, bone, soft tissue and air using a Tissue Probability Map created in SPM12. Images were then smoothed using an isotropic 8mm full width at half maximum Gaussian kernel. Following preprocessing, the Artifact Detection Tools (ART) software package (http://www.nitrc.org/projects/artifact_detect) identified motion outliers ( $>2 \mathrm{~mm}$ movement or $3.5^{\circ}$ rotation); outlier volumes were individually regressed out of the participant's individual model. Additionally, because of the relatively extensive signal loss typically observed in the amygdala, single-subject BOLD fMRI data were only included in subsequent analyses if there was a minimum of $70 \%$ signal coverage in the left and right amygdala, defined using the Automated Anatomical Labeling (AAL) atlas in the WFU PickAtlas Tool, version 1.04 (Maldjian et al., 2003). As the current paper additionally examined 
corticolimbic function within the PFC, participants with less than $70 \%$ coverage in the prefrontal lobe (defined using the AAL atlas) were removed. Lastly, to ensure participants were engaged in the task, participants were excluded if accuracy on the task was less than $70 \%$. Of the 237 participants in the SAND neuroimaging study, usable fMRI data was available for 176 (74\%) participants (Table 1). Participants without usable fMRI data did not differ from participants with usable fMRI data with respect to concurrent family monthly income, earlier measures of parental harshness, or youth gender or race and ethnicity (all $p \mathrm{~s}>.10$ ).

\section{[INSERT TABLE 1 HERE]}

Activation analyses. The general linear model in SPM12 was used to estimate conditionspecific BOLD activation for each individual and scan. Individual contrast images (i.e., weighted sum of the beta images) were then used in second-level random effects models to determine expression-specific reactivity using multiple regression. As the goal of this study was to examine corticolimbic reactivity during threat processing, we present results from the fearful facial expressions $>$ neutral faces and angry facial expressions $>$ neutral faces contrasts. We used two regions of interest (ROIs) to probe the effects of parenting of corticolimbic function: the amygdala and a large PFC mask. We defined the bilateral amygdala using the Automated Anatomical Labeling (AAL) atlas definition in the WFU PickAtlas Tool, version 1.04 (Maldjian et al., 2003). The PFC mask was defined by Brodmann's areas 9 (dorsolateral), 10 (dorsomedial), 11 and 47 (orbitofrontal), 24 and 32 (dorsal anterior cingulate), and 25 (subgenual cingulate), using the WFU PickAtlas Tool, version 1.04 (Maldjian et al., 2003). We used this broad PFC mask to: (1) compare our results to existing studies that used different definitions of the mPFC (Gee et al., 2014; van Harmelen et al., 2014) and to broaden the PFC regions examined, and because (2) the seven Brodmann's Areas we identified have each been shown in 
non-human primate neural tract-tracer studies to be structurally connected to the amygdala (Amaral \& Price, 1984; Ghashghaei et al., 2007) and have been linked structurally to the amygdala in the current sample (Goetschius et al., 2019). We corrected for multiple comparisons using 3dClustSim (Cox et al., 2017; Forman et al., 1995) in AFNI version 16.1.14 (Cox, 1996). Consistent with recommendations by Cox and colleagues (2017), we implemented the spatial autocorrelation function (i.e., the -acf option) to model the spatial smoothness of noise volumes. Group-level smoothing values $(\mathrm{x}=0.55, \mathrm{y}=6.41, \mathrm{z}=13.37)$ were estimated from a random $10 \%$ of participants' individual-model residuals using the program 3dFWHMX, and then averaged across subjects. $3 \mathrm{dClustSim}$ uses a Monte Carlo simulation to provide a threshold that will achieve a family-wise error (FWE) correction for multiple comparisons of $p<.05$ within each ROI. We used a voxel-wise threshold of $p<.001$, which resulted in a threshold of 3 voxels for amygdala activation analyses and 29 voxels for PFC activation analyses. Our cluster thresholds were based on 2-sided tests and used the nearest neighbor definition of "face and edge" (i.e., 3dClustSim command: $\mathrm{NN}=2$ ).

Functional connectivity analysis. Psychological-physiological interaction (PPI) analyses in the generalized PPI toolbox (McLaren et al., 2012) in SPM12 were used to measure amygdala connectivity with regions of the PFC. In a PPI analysis, a design matrix is constructed at the level of the individual with the following columns of variables: (a) a physiological variable that represents the time course of the seed region (i.e., left or right amygdala) across the task, (b) a psychological variable indicating the experimental variable (e.g., onset times for fearful face stimuli), and (c) a product term of the interaction between the physiological and psychological variables. The gPPI toolbox developed by McLaren and colleagues (2012) allows for the simultaneous specification of all task conditions and interactions with the seed region time series 
in the same individual-level model (Friston et al., 1997). This is advantageous because it reduces the number of specified models and the overall type I error rate.

As we were interested in examining changes in amygdala connectivity while participants viewed fearful and angry facial expressions versus neutral faces, we defined the left and right amygdala as seed regions using the AAL definition within the WFU PickAtlas Tool (Maldjian et al., 2003). Two general linear models at the individual level were constructed (i.e., one for each seed region). Using the gPPI toolbox, the time series of the left or right seed region was entered as the physiological variable in the design matrix, the explanatory variables for each of the five conditions in our task (i.e., facial expressions of fear, anger, happy, sad, and neutral faces) were entered as psychological variables, and the five product terms between the amygdala seed and conditions were entered as the interaction terms. We specified two primary contrasts at the individual level: fearful facial expressions interaction term > neutral faces interaction term, and angry facial expressions interaction term $>$ neutral faces interaction term. Practically, this can be interpreted as a difference in slopes: is slope A (i.e., the interaction between amygdala reactivity and the fear/angry condition) greater or less than slope B (i.e., the interaction between amygdala reactivity and the neutral condition). Individual-level slopes (i.e., the betas corresponding to the interaction terms, e.g., fearful facial expressions $\mathrm{X}$ time series of amygdala activation) can then be extracted to determine the direction and strength of connectivity during the two conditions (e.g., fear, neutral). Contrasts from the individual level models were then used in random effects, group-level models to evaluate the impact of harsh parenting in early childhood and changes in harsh parenting across childhood on amygdala-PFC functional connectivity to fearful and angry facial expressions versus neutral faces. These models assess whether harsh parenting is associated with the difference in connectivity between conditions (or the difference in slopes). 
The contrasts of angry facial expressions > baseline, fearful facial expressions > baseline, and neutral faces $>$ baseline were additionally used to confirm that our results were driven by connectivity during the emotion conditions (i.e., fear or anger) rather than the neutral face condition. Only ipsilateral connections between the amygdala and PFC were examined (e.g., left amygdala - left PFC), because neural tracer studies in non-human primates suggests that first order amygdala connections are primarily ipsilateral (Ghashghaei et al., 2007). Thus, we divided the same PFC mask from our activation analyses into left and right PFC masks for use as target regions in connectivity analyses. The same procedure using 3dClustSim (Cox et al., 2017; Forman et al., 1995) in AFNI version 16.1.14 (Cox, 1996) as in the activation analyses was used to correct for multiple comparisons in the functional connectivity analyses. Group level average smoothing values for the left amygdala seed models $(\mathrm{x}=0.55, \mathrm{y}=6.46, \mathrm{z}=13.48)$ and right amygdala seed models $(x=0.56, y=6.44, z=13.48)$ were used to estimate minimum cluster thresholds in the left and right PFC masks $(k=22)$ that would achieve a family-wise error (FWE) correction for multiple comparisons of $p<.05$ within each ROI, using a voxel-wise threshold of $p<.001$.

\section{Analytic Plan}

First, linear growth curve modeling within Mplus version 7.2 (Muthén \& Muthén, 2006) was used to estimate the intercept and slope of maternal harshness. Though our neuroimaging sample was composed of 167 participants, we used all available cases from the core FFCWS ( $N$ $=4,682$ families, where mom was the primary caregiver at the 3-, 5-, and 9-year assessments) to estimate patterns of harsh parenting across childhood. Thus, the estimates of initial levels and changes in parenting behaviors across childhood are derived from a larger nationwide sample with greater power for estimation of these complex models. Cases with at least one data point 
were used in each analysis with the full maximum likelihood (FIML) estimator with robust standard errors, resulting in a sample size of $N=4,144(N=162$ with valid neuroimaging data in the SAND). FIML estimation uses the covariance matrix of all available data to produce unbiased estimates and standard errors in the context of missing data (Enders \& Bandalos, 2001; McCartney et al., 2006). Model fit was considered adequate if the Root Mean Square Error of Approximation (RMSEA) $<0.06$ and the Comparative Fit Index $(\mathrm{CFI})>0.95(\mathrm{Hu} \&$ Bentler, 1999).

To evaluate the effects of harsh parenting in early childhood and changes in harsh parenting behaviors across childhood on corticolimbic function, estimates of the intercept and slope of maternal harshness were extracted from Mplus for use in $2^{\text {nd }}-$ level random effects models within SPM12. First, the intercept or slope of maternal harshness was entered as the primary predictor in a linear regression model, with pubertal status, gender, and race and ethnicity as covariates. To evaluate the unique effects of the intercept/slope, a second set of models was estimated that additionally controlled for the slope/intercept of maternal harshness.

\section{Results}

\section{Estimation of Harsh Parenting across Childhood}

The linear growth curve model of harsh parenting at ages 3, 5 and 9 in the FFCWS $(N=$ 4,144; Figure 2) demonstrated good model fit $\left(\mathrm{X}^{2}[1]=5.62, \mathrm{p}=.02 ; \mathrm{RMSEA}=.03,90 \% \mathrm{CI}\right.$ $[.01, .06] ; \mathrm{CFI}=1.00, \mathrm{TLI}=.99)$ and indicated that, on average, initial levels (i.e., the intercept) of harsh parenting were positive and significantly different from zero (estimated intercept mean $[\mathrm{SD}]=1.23[.02], p<.001)$. On average, levels of harsh parenting decreased from ages 3 to 9 (estimated slope mean $[\mathrm{SD}]=-.09[.003], p<.001)$. Although our primary goal was to examine individual variability from the mean trajectory of the overall group, we tested whether there was 
heterogeneity in growth trajectories using growth mixture modeling (Nagin \& Odgers, 2010). A three-group solution fit the data better than a two-group solution, based on fit indices and classification quality $(\mathrm{AIC}=22964.49, \mathrm{BIC}=22999.16$, entropy $=.79$; posterior probabilities ranged from .84 to .93 ; Lo-Mendell-Rubin adjusted likelihood ratio test $=544.74, p<.001)$. The solution included "low-decreasing" $(n=2041$ [73\%]; intercept $\mathrm{B}[\mathrm{SE}]=.92[.03]$, slope B[SE] = $.11[.01])$, “moderate-decreasing" $(n=950$ [23\%]; intercept $\mathrm{B}[\mathrm{SE}]=1.92[.07]$, slope $\mathrm{B}[\mathrm{SE}]=-$ $.07[.01]$ ), and "high-increasing" (intercept $\mathrm{B}[\mathrm{SE}]=2.37[.17]$, slope $\mathrm{B}[\mathrm{SE}]=.12[.03]$ ) groups. However, the "high-increasing" group was quite small $(n=153[4 \%])$ and even smaller in the neuroimaging subsample $(n=13)$. Thus, we focused our analyses on examining individual variability from the group mean in a single group growth curve.

To inform future research, we examined whether youth in the three trajectory groups differed on non-neural characteristics. One-way ANOVAs revealed significant group differences in pubertal development $(\mathrm{F}(2,161)=4.31, p<.05)$ and parent-reported corporal punishment at age $15(\mathrm{~F}(2,158)=20.83, p<.001)$, but not household income at age 15 . Post hoc Tukey tests showed that youth in the high-increasing group $(\mathrm{N}=13)$ were less pubertally-advanced and exposed to more corporal punishment at age 15 than youth in the low-decreasing $(\mathrm{N}=93)$ and moderate-decreasing $(\mathrm{N}=56)$ groups. Chi-square difference tests revealed no group differences in youth gender, youth race/ethnicity, and parent education or marital status (all $p \mathrm{~s}>.10$ ).

\section{[INSERT FIGURE 2 HERE]}

\section{Harsh Parenting Effects on Corticolimbic Activation}

We next used the estimated intercept and slope terms for each participant to evaluate whether harsh parenting in early childhood (i.e., the intercept, set at age 3) was most strongly associated with amygdala function and whether changes in harsh parenting across childhood 
(i.e., the slope) were most predictive of PFC function during emotional face processing at age 15. Across all models, the associations between harsh parenting and corticolimbic activation were specific to angry (i.e., anger versus neutral contrast), rather than fearful facial expressions (i.e., fear versus neutral contrast). First, greater harsh parenting in early childhood was associated with less left amygdala (but not PFC) reactivity to angry facial expressions versus neutral faces (see Table 2; Figure 3), controlling for changes in harsh parenting across childhood (i.e., the slope term) and harsh parenting at age 15 (i.e., the same age as the neuroimaging data collection). In contrast, increases in harsh parenting from ages 3 to 9 , controlling for harsh parenting in early childhood (i.e., the intercept) and harsh parenting at age 15, were associated with less right dorsal anterior cingulate cortex (ACC), but not amygdala, reactivity to angry facial expressions versus neutral faces (Table 2; Figure 3).

\section{[INSERT TABLE 2 HERE]}

[INSERT FIGURE 3 HERE]

\section{Harsh Parenting Effects on Corticolimbic Connectivity}

Consistent with the corticolimbic activation results, all models linking harsh parenting to amygdala-PFC connectivity during emotional face processing were specific to the angry versus neutral face contrast. In line with our hypotheses, both greater harsh parenting in early childhood and increases in harsh parenting from ages 3 to 9 were uniquely (i.e., accounting for their overlap) associated with greater amygdala-PFC connectivity during angry face processing than neutral face processing (Table 2). After accounting for harsh parenting at age 15 , however, only changes in harsh parenting across childhood (i.e., the slope term) were associated with amygdala-PFC connectivity during angry face processing. To determine the direction of 
amygdala-PFC connectivity (i.e., whether activation in the seed and target region was positively or negatively coupled), we extracted the connectivity estimates during each condition separately. As shown in Figure 3, increases in harsh parenting across childhood were associated with more positive left amygdala - left OFC and left amygdala - left mPFC connectivity during angry face processing but not neutral face processing (Table 2; Figure 4).

[INSERT FIGURE 4 HERE]

\section{Post-hoc Exploratory Analyses}

Cumulative exposure to harsh parenting. Although our results suggest that the timing of exposure to harsh parenting is important for corticolimbic function in adolescence, our results could also reflect cumulative risk effects (Sameroff et al., 1987). That is, it may be that youth with the highest levels of harsh parenting in early childhood were also exposed to the highest levels of harsh parenting at subsequent ages and, thus, our results could be accounted for by a cumulative effect of harsh parenting across childhood. Using methods traditional to cumulative risk research (Evans et al., 2013), we calculated the number of waves (i.e., 3-, 5- , and 9-year waves; possible cumulative risk score $0-3$ ) during which an individual scored in the top quartile of harsh parenting. Of the 162 families with valid harsh parenting data at all three waves, most families $(62.3 \%)$ were low risk across all three waves. Twenty-eight (17.3\%) and 21 (13\%) families were at risk in one or two waves, respectively, and $12(7.4 \%)$ families scored in the top quartile of harsh parenting at all three waves. Controlling for participant demographics at age 15, we examined whether cumulative risk scores were associated with (1) amygdala activation, (2) PFC activation, and (3) amygdala-PFC connectivity during angry versus neutral face processing at age 15. Consistent with the notion that timing of exposure to harsh parenting is important for 
corticolimbic development, the cumulative harsh parenting risk score was not associated with amygdala or PFC activation or connectivity (no clusters above threshold).

Gender differences. Based on previous research (Everaerd et al., 2016; Tottenham \& Sheridan, 2009; Whittle et al., 2017), we examined possible gender differences in the effects of harsh parenting on corticolimbic activation and connectivity during angry versus neutral face processing via exploratory analyses. First, we constructed interaction terms between the intercept/slope of harsh parenting and gender. Two linear regression models were used to estimate the effects of each interaction term on corticolimbic activation and connectivity, accounting for the main effects of the harsh parenting intercept and slope (both mean-centered), gender, pubertal development, and race/ethnicity. There were no statistically significant association between the interaction terms and amygdala or prefrontal reactivity to angry versus neutral faces, or condition-specific amygdala-prefrontal connectivity. To stimulate future work in this area, we re-analyzed our data stratified by gender. Although there were no associations between harsh parenting and amygdala or prefrontal reactivity in boys $(n=75)$ or girls $(n=87$; likely due to the reduced sample size/power), the effects of harsh parenting on left amygdala-left prefrontal connectivity were observed in girls only. Consistent with the pattern of findings in the total sample, increases in harsh parenting across childhood (accounting for initial levels of harsh parenting and parenting at age 15) were associated with stronger positive left amygdala - left OFC $([\mathrm{x}, \mathrm{y}, \mathrm{z}]=[-18,56,24], t=4.94, k=400)$ and left amygdala - left $\mathrm{mPFC}([\mathrm{x}, \mathrm{y}, \mathrm{z}]=[-22$, $56,-8], t=3.88, k=23$ ) connectivity during angry but not neutral face processing. Although these findings suggest that future work should explore gender differences in parenting effects on brain development, we caution readers that these results are likely underpowered and were exploratory in nature. 


\section{Discussion}

The current study examined how harsh parenting behaviors change across childhood in a large, population-based sample of sociodemographically-diverse families, and explored how harsh parenting in early childhood and changes in harsh parenting across childhood were associated with subsequent corticolimbic function during adolescence. One of the study's strengths was the integration of data from an existing nationwide study of nearly 5,000 families followed prospectively from birth with neuroimaging data from a subsample recruited during adolescence. Consistent with prior research on trajectories of parenting behaviors during shorter developmental windows (Dallaire \& Weinraub, 2005; Kim et al., 2010), harsh parenting was initially high at age 3 and decreased thereafter through age 9. Moreover, consistent with animal models and theory (Debiec \& Sullivan, 2017; Lupien et al., 2009; Tottenham, 2015), we found that harsh parenting in early childhood was associated with less amygdala activation during socioemotional processing at age 15, whereas increases in harsh parenting from ages 3 to 9 were associated with less activation in the dorsal ACC at age 15. In stringent models that accounted for harsh parenting age 15 (i.e., concurrent to the neuroimaging assessment), only increases in harsh parenting across childhood were associated with stronger positive amygdala-PFC connectivity during angry versus neutral face processing.

\section{The Trajectory of Harsh Parenting across Childhood}

In a population-based sample of families followed prospectively across childhood (Reichman et al., 2001), maternal harshness changed from ages 3 to 9 in ways that mirror the developmental competencies of each developmental stage. On average, maternal harshness was greatest at age 3 , when children are increasingly mobile and normatively evince greater emotionality (Shaw \& Bell, 1993). Thereafter, from ages 3 to 9, maternal harshness decreased. 
During middle childhood (5 to 12 years), affective expression within the parent-child dyad has been shown to decrease, where both children and parents show less overt negative behaviors (e.g., coercion, emotional outbursts) (Collins et al., 2005; Forehand \& Jones, 2002; Shanahan et al., 2007). Our results in the nationwide FFCWS build upon previous work that tracked changes in parenting behaviors during shorter developmental windows, such as during infancy and early childhood (Dallaire \& Weinraub, 2005; Lipscomb et al., 2011). Critically, reliance on a population-based sample of families over-sampled for sociodemographic risk suggests that these patterns of maternal harshness across childhood are reflective of the broader population of U.S. families of living in urban and impoverished contexts, who are exposed to substantial environmental adversity (McLoyd, 1998).

\section{Developmental Timing Modulates Adversity Effects on Corticolimbic Function}

Although several recent reviews have posited that exposure to harsh contexts impacts corticolimbic function in a timing-specific manner (Lupien et al., 2009; Tottenham, 2015), our study is one of the first to empirically test this hypothesis in humans using repeated measures of harsh parenting across childhood in a population-based sample of low-income adolescents. We found that harsh parenting in early childhood was associated with less amygdala, but not PFC or ACC, activation, and that increases in harsh parenting thereafter were associated with less dorsal ACC, but not amygdala, activation during angry face processing. That we found no effects of cumulative exposure to harsh parenting across childhood on corticolimbic function reiterates the importance of timing of exposure for subsequent amygdala and prefrontal function. Much of the theoretical rationale for the notion of "sensitive periods" emerged from foundational work in humans documenting the developmental trajectories of subcortical and cortical brain development (Gilmore et al., 2012), and from animal studies wherein environmental exposure 
can be manipulated. For example, rhesus monkeys separated from their mother at 1-week versus 1-month of age or control animals (no separation), showed a significant decrease in gene expression in lateral and basal amygdala nuclei, more so than in prefrontal regions (Sabatini et al., 2007). In contrast to subcortical regions such as the amygdala, regions of the PFC develop into adulthood (Lenroot \& Giedd, 2006; Sowell et al., 2003). Structural MRI studies have shown that gray matter volume in the PFC increases during the pre-adolescent period, followed by postadolescent decrease (Giedd et al., 1999); such volumetric changes correspond with increasing activation in the ACC and mPFC, and parallel behavioral improvements in executive functioning and emotion regulation (Casey et al., 2008). Consistent with the notion that windows of vulnerability occur during developmental stages marked by rapid change (Andersen \& Teicher, 2008), it may be that pre-pubertal youth experience neural reorganization following environmental adversity. Our results are consistent with the existing structural MRI studies in this areas that have reported similar timing-specific results for the effects of sexual abuse on subcortical and prefrontal volumes: abuse that occurred between ages 3 and 5 was associated with hippocampal, but not PFC volume, whereas abuse that occurred between ages 14 and 16 was associated with PFC, but not hippocampal, volume (Andersen et al., 2008; Pechtel et al., 2014). Our study extends this research to corticolimbic function and a measure of a more common form of childhood adversity - harsh parenting. In a recent paper (Gard et al., 2020), we replicated the timing effects presented here, using another unfortunately common experience faced by children in the U.S: neighborhood disadvantage. The effects persisted above-andbeyond harsh parenting (see Gard et al., 2017, for a similar conclusion in a different sample), suggesting that both harsh parenting and living in a disadvantage neighborhood sculpt corticolimbic function in a timing-specific manner. 


\section{Inconsistencies in Adversity - Amygdala Function Associations}

That harsh parenting in early childhood was associated with less threat-related amygdala reactivity was in the opposite direction to our hypothesis and most, but not all, previous research. A meta-analysis found that individuals exposed to childhood maltreatment exhibited greater amygdala activation to threatening emotional facial expressions (Hein \& Monk, 2017). In contrast, three studies that operationalized childhood adversity as family income, family conflict, or harsh parenting reported that greater adversity was associated with less amygdala reactivity to threatening facial expressions (Gard et al., 2017; Holz et al., 2017; Javanbakht et al., 2015), consistent with our results. Moreover, a recent study found that individuals who were physically abused or neglected evinced greater threat-related amygdala reactivity, whereas individuals who experienced both types of maltreatment showed less threat-related amygdala reactivity compared to controls (Puetz et al., 2019). Collectively, this research suggests that the severity, frequency, and type of adversity may modulate the effects on neural function, particularly with regards to the direction of associations within the amygdala. A wealth of literature indicates that chronic exposure to early life adversity leads to hypoactivation of physiological stress responses (Loman \& Gunnar, 2010). Similarly, although amygdala sensitivity to environmental signals of threat or danger is adaptive in the short-term, particularly for youth living in adverse contexts, persistent hyperactivation of physiological response systems (e.g., the hypothalamic pituitaryadrenocortical axis) can lead to a wide array of diseases (McEwen \& McEwen, 2017). Thus, tentatively, blunted amygdala reactivity to threatening facial expressions following exposure to chronic, daily adversities (e.g., low family income, harsh parenting) may be an adaptive response that facilitates allostasis and minimizes exposure to neurotoxic physiological hormones (e.g., cortisol). 


\section{Associations between Harsh Parenting and Prefrontal Function}

We also found that increases in harsh parenting across childhood were associated with less mPFC reactivity (centered in the dorsal ACC) during socioemotional processing, consistent with our hypotheses and a study by van Harmelen and colleagues (2014). Dorsal regions of the PFC/ACC are thought to support the cognitive components of emotion processing, including appraisal during passive attendance to emotional facial expressions (Etkin et al., 2011). One interpretation of our results is that youth exposed to recurrent harsh parenting behaviors across childhood fail to recruit the $\mathrm{dACC}$ while viewing threatening facial expressions. Transcranial magnetic stimulation applied over the dACC (BAs 24 and 32) has been shown to impair discrimination of angry faces (Harmer et al., 2001), lending support for the idea that failed recruitment of the dACC generates inappropriate responses to threatening stimuli. Indeed, multiple forms of psychopathology have been associated with less dACC reactivity during angry face processing, including antisocial behavior (Hyde et al., 2013; Yang \& Raine, 2009) and generalized anxiety disorder (Mochcovitch et al., 2014). Although our results suggest that the neural effects of harsh parenting were centered in the mPFC/dACC, several other studies have reported negative associations between childhood adversity and neural activation in the dlPFC/inferior frontal gyrus (Fonzo et al., 2016; Liberzon et al., 2015), highlighting potentially diffuse effects of adversity on PFC function. Identification of dorsal rather than ventral regions of the mPFC in the current study could reflect the fact that our emotional faces matching task captured cognitive (i.e., perceptual processing) rather than regulatory components of emotion processing (Etkin et al., 2011; Fuster, 2001).

\section{Associations between Harsh Parenting and Amygdala-Prefrontal Connectivity}


In contrast to our hypothesis, we found that increases in harsh parenting across childhood were associated with stronger positive, rather than weaker negative, amygdala-prefrontal connectivity (centered on Brodmann's Areas $10[\mathrm{OFC}]$ and $9[\mathrm{mPFC}]$ ) during angry compared to neutral face processing. Several studies using task-based or resting-state fMRI have found that children exhibit positive amygdala-mPFC connectivity during threat processing (Gee, Humphreys, et al., 2013). Positive amygdala-mPFC connectivity has been associated with anxiety in children (Demenescu et al., 2013; Gee et al., 2013) and internalizing and externalizing behaviors in adults (Gard et al., 2018; Waller et al., 2018). Adolescents and adults, in contrast, evince stronger negative amygdala-mPFC connectivity (Gee, Humphreys, et al., 2013). Previous research has shown that youth exposed to maltreatment or previous institutionalization show stronger negative amygdala-mPFC connectivity during threat processing, supporting a "stressacceleration" hypothesis (Gee, Gabard-Durnam, et al., 2013; Jedd et al., 2015; Peverill et al., 2019). However, our results suggest that the youth in our sample exposed to harsh parenting are not maturing earlier but, rather, show a potentially "immature" pattern of amygdala-prefrontal connectivity reflective of younger children.

\section{Specificity of Angry Facial Expressions}

That the effects of harsh parenting on corticolimbic function were specific to the angry facial expressions versus neutral faces contrast suggests that more research is needed to determine the affective specificity of adversity effects on corticolimbic function. Maheau and colleagues (2010) also found that the effects of childhood maltreatment on amygdala function were specific to angry facial expressions, whereas Gard et al. (2017) and van Harmelen et al. (2013) did not report stronger effects for angry face processing. Previous reports indicate that physically abused children may process angry facial expressions differently than non-maltreated 
controls (Pollak \& Sinha, 2002; Pollak \& Tolley-Schell, 2003). Compared to non-maltreated children, physically abused children may require less perceptual information to correctly identify facial expressions of anger (Pollak \& Sinha, 2002), and respond more quickly to targets cued by angry faces versus happy faces (Pollak \& Tolley-Schell, 2003). More research is needed to determine whether certain features of adversity or environmental context shape the associations with (and potential specificity for) different facial expressions. This is particularly important as several meta-analyses highlight the modulating role of emotional valence in fMRI studies of psychopathology (e.g., Groenewold et al., 2013)

\section{Limitations and Future Directions}

Despite the use of a large population-based sample of sociodemographically-diverse families followed from birth through adolescence, integration of repeated measures of harsh parenting across childhood with linear growth curve modeling, and examination of corticolimbic activation and connectivity within the same analyses, several limitations warrant consideration.

First, although our results suggest that the timing of exposure to harsh parenting is important for subsequent corticolimbic function, interpretations of our results as evidence for "sensitive periods" should be tempered. Such a claim would require repeated measures of neural function in addition to repeated measures of harsh parenting (Andersen \& Teicher, 2008). Procuring measures of task-based corticolimbic function in early childhood is challenging; studies rarely collect such data in children younger than 5 years due to motion and attention constraints (Graham et al., 2015). In recent years, other imaging modalities such as resting-state or sleeping fMRI, have been successfully translated into younger populations including infants (Graham et al., 2015); such approaches are promising for evaluating sensitive periods of environmental effects on brain development. Nevertheless, our results should be interpreted within the context 
of robust animal experiments documenting sensitive periods of adversity effects on corticolimbic development (reviewed by Callaghan \& Tottenham, 2016) and longitudinal structural MRI studies (reviewed by Teicher \& Samson, 2016). Relatedly, although theories of corticolimbic development highlight early childhood and adolescence as two potential windows of vulnerability, we were unable to include harsh parenting during adolescence in our linear growth curve models. Although the FFCWS collected data at age 15, there was only one harsh parenting item that overlapped with the data collected at ages 3, 5, and 9. We included a different but comparable measure of maternal physical aggression at age 15 from the FFCWS-SAND cohort, and found that this measure of harsh parenting was not associated with concurrent corticolimbic function. Nevertheless, replications of our results would benefit from more intensive data collection across both childhood and adolescence.

Third, harsh parenting is only one type of environmental exposure thought to impact functional brain development; neighborhood- and family-level socioeconomic disadvantage, maternal psychopathology, and inter-parental conflict are just some examples of adversities that often co-occur with harsh parenting (Green et al., 2010). Nevertheless, there is good reason to believe that parenting behaviors are relevant targets for understanding how environmental stress becomes biologically embedded to predict maladaptive youth socioemotional outcomes. The Family Stress Model posits that parenting behaviors (i.e., low warmth/nurturance, high harshness) mediate the negative effects of socioeconomic disadvantage on youth outcomes (Conger et al., 1994); this model has been supported across a range of contexts - within urban and rural samples, cross-culturally, in racially- and ethnically-diverse samples, in two-parent and single-parent families, and using cross-sectional and longitudinal data (reviewed by Masarik \& Conger, 2017; see Gard et al., 2020 for a recent application in the FFCWS). Several structural 
MRI studies have shown that parenting behaviors can mediate (Luby et al., 2013) and moderate (Whittle et al., 2017) the effects of socioeconomic status (SES) on youth brain development. For example, using repeated measures of amygdala volume, Whittle and colleagues (2017) showed that, among adolescents from low SES backgrounds, positive parenting attenuated the agerelated increase in amygdala volume. Although some research has shown that the impact of parenting behaviors on youth corticolimbic function is independent of other correlated adversities such as low family income and maternal depression (Gard et al., 2017), more research is needed to evaluate this claim. This literature would also benefit from exploration of different types of parenting behaviors beyond physical harshness (e.g., psychological coercion, warmth).

The present study extends previous research by documenting how maternal harsh parenting changes across childhood in a population-based sample of socio-demographically diverse families, and highlights that the effects of harsh parenting on corticolimbic function depend on timing of exposure and the neural region examined. We present one pathway by which environmental adversity may become biologically-embedded to predict maladaptive youth socioemotional behaviors (McEwen \& McEwen, 2017). Future research will benefit from study designs that boast repeated measures of neural function, examinations of how severity and chronicity of adversity impacts corticolimbic function, and the efficacy of parenting interventions on changes in brain development within emotion-processing-related regions. 
Table 1. Sources of fMRI data loss

\begin{tabular}{|c|c|c|}
\hline & Number lost & Participants with data \\
\hline Original sample & & 237 \\
\hline \multicolumn{3}{|l|}{ Sample with imaging data } \\
\hline - $\quad$ Refused MRI & 16 & \\
\hline - $\quad$ Exceeded MRI table weight limit & 3 & \\
\hline - Medical restriction & 1 & \\
\hline - Braces or other metal in body & 7 & \\
\hline - $\quad$ Risk of pregnancy & 1 & \\
\hline $\begin{array}{l}\text { - Excluded for diagnosis of Autism } \\
\text { Spectrum Disorder }\end{array}$ & 2 & \\
\hline - Incomplete fMRI data & 4 & \\
\hline Total lost & 34 & 203 \\
\hline \multicolumn{3}{|l|}{ Sample with usable imaging data } \\
\hline - Alternate version of faces task & 2 & \\
\hline $\begin{array}{l}\text { - Low amygdala coverage }(<70 \% \text { left or } \\
\text { right amygdala) }\end{array}$ & 4 & \\
\hline - Low prefrontal cortex coverage $(<90 \%)$ & 4 & \\
\hline - Functional image distortion & 7 & \\
\hline - $\quad$ Low accuracy $(<70 \%)$ & 18 & \\
\hline - Activation outlier & 1 & \\
\hline Total lost & 36 & 167 \\
\hline
\end{tabular}

Note. Low amygdala coverage was defined using the AAL definition of the bilateral amygdala from the WFU PickAtlas Tool (Maldjian et al., 2003). Low prefrontal cortex coverage was defined using a mask of the prefrontal lobe from the WFU PickAtlas Tool (Maldjian et al., 2003). 
Table 2. Harsh parenting in early childhood and changes in harsh parenting across childhood predict corticolimbic activation and connectivity during angry face processing

\section{Activation Results}

\begin{tabular}{|c|c|c|c|}
\hline Predictor & $\begin{array}{l}\text { Direction of } \\
\text { relationship }\end{array}$ & $\begin{array}{c}\text { Bilateral Amygdala } \\
(\mathrm{x}, \mathrm{y}, \mathrm{z}), t \text { and voxel } \\
\text { extent }(k)\end{array}$ & $\begin{array}{l}\text { Prefrontal Cortex }(\mathrm{x}, \mathrm{y}, \mathrm{z}), t \\
\text { and voxel extent }(k)\end{array}$ \\
\hline $\begin{array}{l}\text { Intercept of Harsh } \\
\text { Parenting }\end{array}$ & Negative & $\begin{array}{c}\text { Left: }(-26,-4,-22) \\
t=3.67, k=14^{*}\end{array}$ & no suprathreshold clusters \\
\hline $\begin{array}{l}\text { Slope of Harsh } \\
\text { Parenting }\end{array}$ & Negative & $\begin{array}{l}\text { no suprathreshold } \\
\text { clusters }\end{array}$ & $\begin{array}{l}\text { Right dorsal ACC (BA32) } \\
(6,32,22), t=3.66, k=50^{*}\end{array}$ \\
\hline \multicolumn{4}{|c|}{ Connectivity Results } \\
\hline Predictor & $\begin{array}{l}\text { Direction of } \\
\text { relationship }\end{array}$ & $\begin{array}{c}\text { Left Amygdala Seed } \\
\text { Region - Left PFC }\end{array}$ & $\begin{array}{l}\text { Right Amygdala Seed } \\
\text { Region - Right PFC }\end{array}$ \\
\hline $\begin{array}{l}\text { Intercept of Harsh } \\
\text { Parenting }\end{array}$ & Positive & $\begin{array}{l}\text { Left IFG/Insula (BA47): } \\
\begin{array}{c}(-30,20,-6), t=3.98 \\
k=29\end{array}\end{array}$ & no suprathreshold clusters \\
\hline $\begin{array}{l}\text { Slope of Harsh } \\
\text { Parenting }\end{array}$ & Positive & $\begin{array}{c}\text { Left OFC (BA10): } \\
(-8,46,16), t=3.47 \\
k=16^{*} \\
\text { Left mPFC (BA9): } \\
(-12,58,32), t=4.26, \\
k=27^{*}\end{array}$ & $\begin{array}{l}\text { Right MCC (BA 24): } \\
(6,0,32), t=3.62, k=28\end{array}$ \\
\hline
\end{tabular}

Note. $N=162$. All models controlled for youth gender, race, pubertal status, and the intercept/slope term. For activation, the results of the intercept and slope models of harsh parenting on corticolimbic reactivity were driven by less activation to angry facial expressions versus baseline (intercept model: $p_{\text {voxel }}<.05,[-24,-2,-22], t=2.29, k=59$; slope model: $p_{\text {voxel }}<.05$, $[14,34,22], t=3.21, k=126)$, rather than greater activation to neutral facial expressions versus baseline (no clusters at $p_{\text {voxel }}<.05$ ). For connectivity, the results of the intercept and slope models of harsh parenting on corticolimbic connectivity were driven by greater amygdala-PFC connectivity during angry face versus baseline processing (left amygdala seed slope model: $p_{\text {voxel }}$ $<.05,[-8,46,16], t=2.68, k=232$; left amygdala intercept model: $p_{\text {voxel }}<.01,[-2,53,4], t=3.13$, $k=85$ ), rather than less amygdala-PFC connectivity during neutral face processing versus baseline (no clusters at $p_{\text {voxel }}<.05$ ). Note that zero-order correlations between the intercept and slope of harsh parenting and harsh parenting at age 15 ranged from $.25<|r|<.29$.

*significant after accounting for harsh parenting at age 15 (concurrent to the neuroimaging assessment) 
Figure 1. Implicit emotional faces matching paradigm

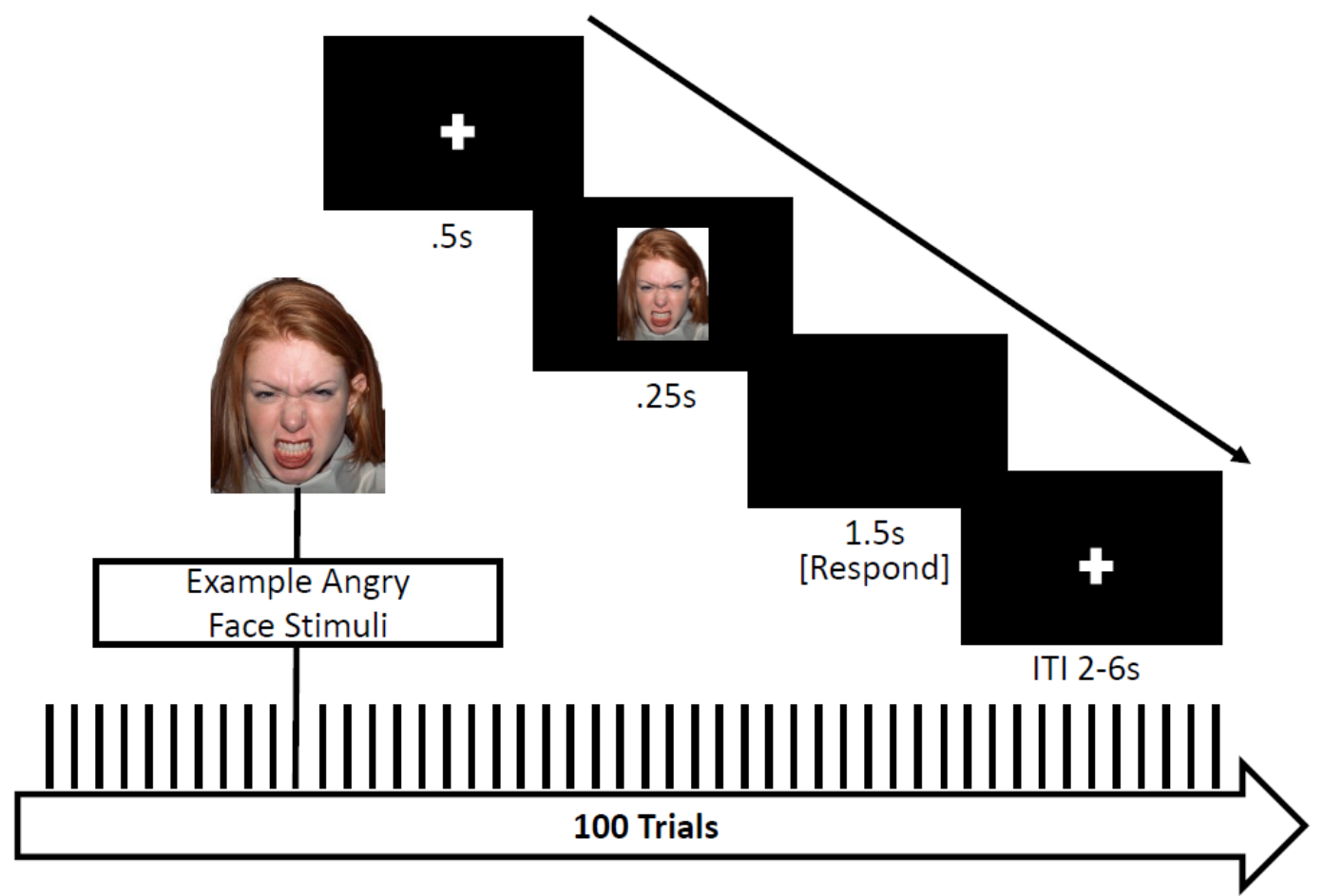

Note. This event-related task design included 100 trials, 20 each of the following facial expressions: angry, fearful, sad, neutral, and happy. Total task time was 8.75 minutes. 
Figure 2. Individual observed values of harsh parenting across childhood

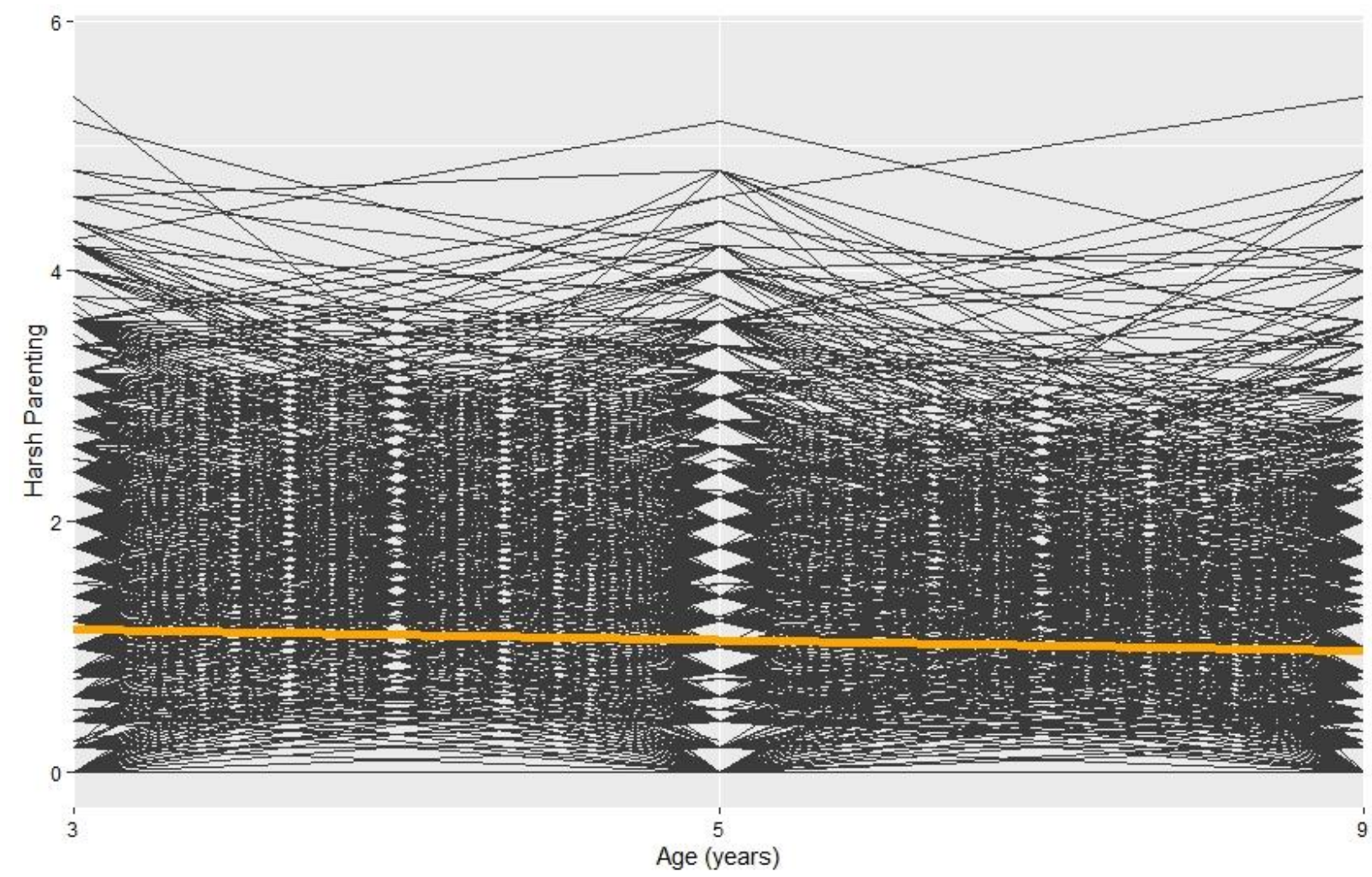

Note. $N=4,144$. Spaghetti plot of individual observed values of harsh parenting at ages 3, 5, and 9 years. Group average trajectory depicted in red. Model fit: $\mathrm{X}^{2}(1)=5.62, p=.02$; RMSEA = $.03,90 \% \mathrm{CI}(.01, .06)$; CFI $=1.00, \mathrm{TLI}=.99, \mathrm{SRMR}=.01$. Loadings for the latent slope factor were specified as 0 (age 3), 2 (age 5), and 6 (age 9), and all loadings for the latent intercept factor were set equal to 1 . 
Figure 3. Harsh parenting in early childhood and increases in harsh parenting across childhood are associated with lesser corticolimbic activation during angry face processing

(A)

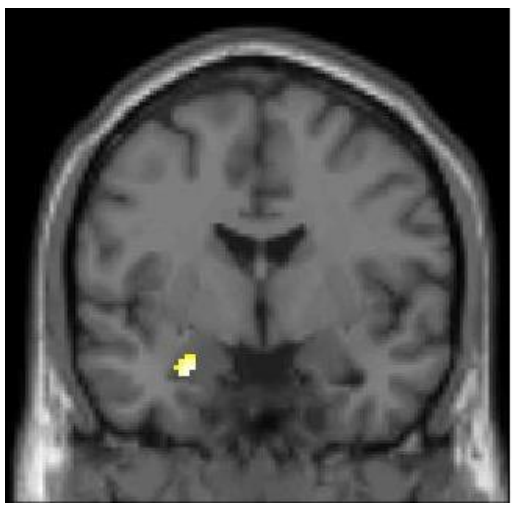

(B)

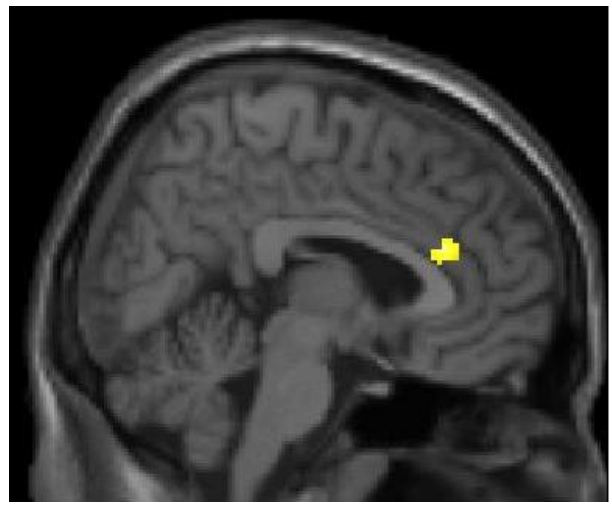

Note. $N=159$. Results are from the most stringent models that control for youth gender, race, pubertal status, the intercept/slope term, and harsh parenting at age 15. (A) Greater harsh parenting in early childhood (i.e., the intercept from a linear growth curve model, set at age 3) associated with lesser left amygdala reactivity to angry versus neutral faces; $(\mathrm{x}, \mathrm{y}, \mathrm{z})=(-26,-4,-$ 22), $t=3.91, k=41$. (B). Increases in harsh parenting from ages 3 to 9 associated with lesser bilateral dorsal anterior cingulate reactivity to angry versus neutral faces; right $(\mathrm{x}, \mathrm{y}, \mathrm{z})=$ $(6,32,22), t=3.66, k=151$; left $(\mathrm{x}, \mathrm{y}, \mathrm{z})=(-8,34,18), t=3.39, k=119$. 
Figure 4. High initial levels and increases in harsh parenting across childhood are associated with more positive left amygdala-left prefrontal cortex connectivity during angry face processing

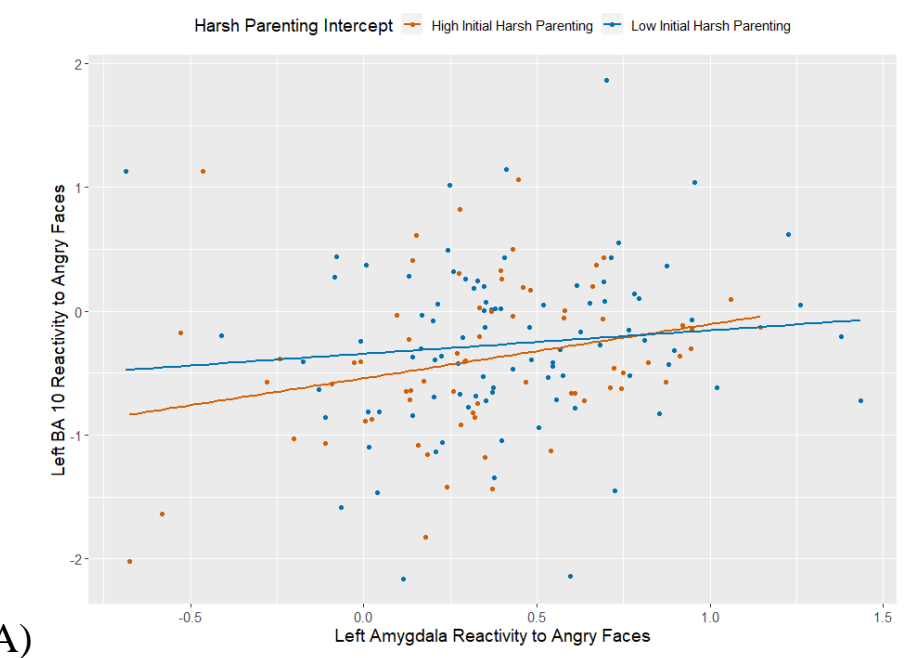

(A)

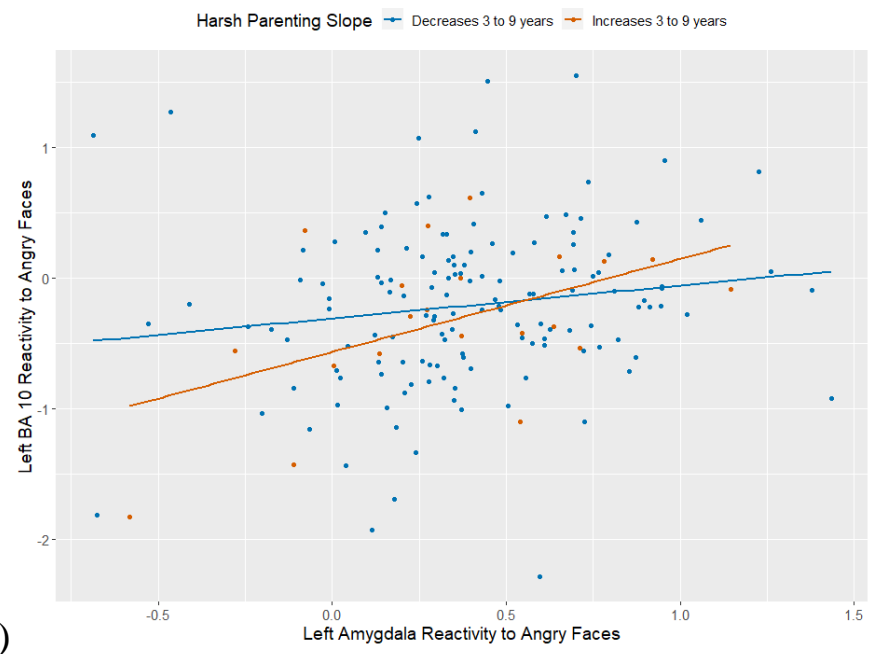

(B)

Left Amygdala Reactivity to Angry Face

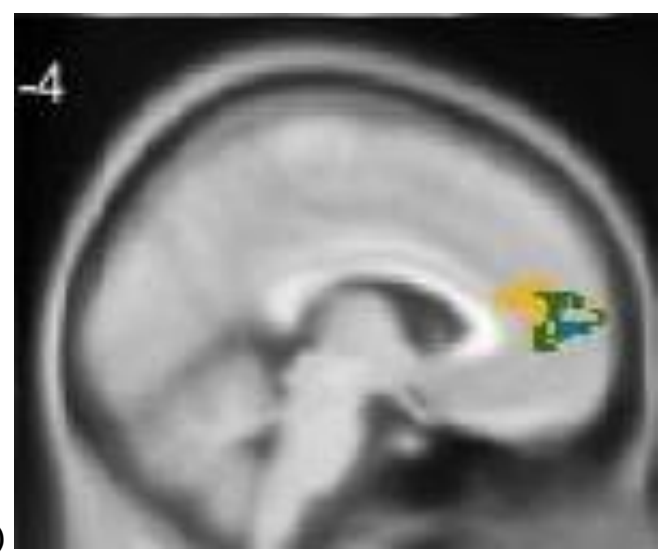

Note. $N=159 . \mathrm{BA}=$ Brodmann's Area. Results are from the most stringent models that control for youth gender, race, pubertal status, the intercept/slope term, and harsh parenting at age 15 . (A) Greater harsh parenting in early childhood (i.e., the intercept) associated with more positive 
left amygdala-left orbitofrontal (BA10) connectivity during angry face processing in adolescence; $(\mathrm{x}, \mathrm{y}, \mathrm{z})=(-16,68,8), t=3.44, k=198$. (B) Increases in harsh parenting from ages three to nine (i.e., the slope) associated with more positive left amygdala-left orbitofrontal

(BA10) connectivity during angry face processing in adolescence; $(\mathrm{x}, \mathrm{y}, \mathrm{z})=(-8,46,16), t=3.75$, $k=358$ (C) Image of identified clusters in (A) and (B) where yellow refers to the intercept results, blue refers to the slope result, and green areas show their overlap. 


\section{References}

Ainsworth, M. S. (1979). Infant-mother attachment. American Psychologist, 34(10), 932.

Alarcón, G., Cservenka, A., Rudolph, M. D., Fair, D. A., \& Nagel, B. J. (2015). Developmental sex differences in resting state functional connectivity of amygdala sub-regions. NeuroImage, 115, 235-244. https://doi.org/10.1016/j.neuroimage.2015.04.013

Amaral, D. G., \& Price, J. L. (1984). Amygdalo-cortical projections in the monkey (Macaca fascicularis). Journal of Comparative Neurology, 230(4), 465-496. https://doi.org/10.1002/cne.902300402

Andersen, S. L., \& Teicher, M. H. (2008). Stress, sensitive periods and maturational events in adolescent depression. Trends in Neurosciences, 31(4), 183-191. https://doi.org/10.1016/j.tins.2008.01.004

Andersen, S. L., Tomada, A., Vincow, E. S., Valente, E., Polcari, A., \& Teicher, M. H. (2008). Preliminary Evidence for Sensitive Periods in the Effect of Childhood Sexual Abuse on Regional Brain Development. The Journal of Neuropsychiatry and Clinical Neurosciences, 20(3), 292-301. https://doi.org/10.1176/jnp.2008.20.3.292

Benes, F. M. (2010). Corticolimbic circuitry and psychopathology. In Human Behavior, Learning, and the Developing Brain: Atypical Development (1st ed.). The Guilford Press.

Blair, C., \& Diamond, A. (2008). Biological processes in prevention and intervention: The promotion of self-regulation as a means of preventing school failure. Development and Psychopathology, 20(3), 899-911. https://doi.org/10.1017/S0954579408000436

Blakemore, S.-J. (2008). The social brain in adolescence. Nature Reviews Neuroscience, 9(4), 267-277. https://doi.org/10.1038/nrn2353

Bowlby, J. (1982). Attachment and loss: Retrospect and prospect. American Journal of Orthopsychiatry, 52(4), 664. 
Bugental, D. B., \& Grusec, J. E. (2006). Socialization Processes. In Handbook of Child Psychology (6th ed., Vol. 3, p. 63). John Wiley \& Sons.

Bzdok, D., Laird, A. R., Zilles, K., Fox, P. T., \& Eickhoff, S. B. (2013). An investigation of the structural, connectional, and functional subspecialization in the human amygdala: Parcellation of the Human Amygdala. Human Brain Mapping, 34(12), 3247-3266. https://doi.org/10.1002/hbm.22138

Callaghan, B. L., \& Tottenham, N. (2016). The Neuro-Environmental Loop of Plasticity: A Cross-Species Analysis of Parental Effects on Emotion Circuitry Development Following Typical and Adverse Caregiving. Neuropsychopharmacology, 41(1), 163-176. https://doi.org/10.1038/npp.2015.204

Casey, B. J., Jones, R. M., \& Hare, T. A. (2008). The Adolescent Brain. Annals of the New York Academy of Sciences, 1124(1), 111-126. https://doi.org/10.1196/annals.1440.010

Cicchetti, D., \& Toth, S. L. (2009). The past achievements and future promises of developmental psychopathology: The coming of age of a discipline. Journal of Child Psychology and Psychiatry, 50(1-2), 16-25.

Coccaro, E. F., McCloskey, M. S., Fitzgerald, D. A., \& Phan, K. L. (2007). Amygdala and orbitofrontal reactivity to social threat in individuals with impulsive aggression. Biological Psychiatry, 62(2), 168-178.

Colich, N. L., Williams, E. S., Ho, T. C., King, L. S., Humphreys, K. L., Price, A. N., Ordaz, S. J., \& Gotlib, I. H. (2017). The association between early life stress and prefrontal cortex activation during implicit emotion regulation is moderated by sex in early adolescence. Development and Psychopathology, 29(5), 1851-1864. https://doi.org/10.1017/S0954579417001444 
Collins, W. A., Madsen, S. D., \& Susman-Stillman, A. (2005). Parenting during middle childhood. In Handbook of Parenting: Volume I: Children and Parenting (pp. 73-101). Lawrence Erlbaum Associates.

Conger, R. D., Ge, X., Elder, G. H., Lorenz, F. O., \& Simons, R. L. (1994). Economic Stress, Coercive Family Process, and Developmental Problems of Adolescents. Child Development, 65(2), 541. https://doi.org/10.2307/1131401

Cox, R. W. (1996). AFNI: Software for Analysis and Visualization of Functional Magnetic Resonance Neuroimages. Computers and Biomedical Research, 29(3), 162-173. https://doi.org/10.1006/cbmr.1996.0014

Cox, R. W., Chen, G., Glen, D. R., Reynolds, R. C., \& Taylor, P. A. (2017). FMRI Clustering in AFNI: False-Positive Rates Redux. Brain Connectivity, 7(3), 152-171. https://doi.org/10.1089/brain.2016.0475

Dallaire, D. H., \& Weinraub, M. (2005). The stability of parenting behaviors over the first 6 years of life. Early Childhood Research Quarterly, 20(2), 201-219. https://doi.org/10.1016/j.ecresq.2005.04.008

Darling, N., \& Steinberg, L. (1993). Parenting style as context: An integrative model. Psychological Bulletin, 113(3), 487.

Debiec, J., \& Sullivan, R. M. (2017). The neurobiology of safety and threat learning in infancy. Neurobiology of Learning and Memory, 143, 49-58. https://doi.org/10.1016/j.nlm.2016.10.015

Demenescu, L. R., Kortekaas, R., Cremers, H. R., Renken, R. J., van Tol, M. J., van der Wee, N. J. A., Veltman, D. J., den Boer, J. A., Roelofs, K., \& Aleman, A. (2013). Amygdala activation and its functional connectivity during perception of emotional faces in social 
phobia and panic disorder. Journal of Psychiatric Research, 47(8), 1024-1031. https://doi.org/10.1016/j.jpsychires.2013.03.020

Ekman, P., \& Friesen, W. V. (1976). Measuring facial movement. Environmental Psychology and Nonverbal Behavior, 1(1), 56-75. https://doi.org/10.1007/BF01115465

Enders, C., \& Bandalos, D. (2001). The Relative Performance of Full Information Maximum Likelihood Estimation for Missing Data in Structural Equation Models. Structural Equation Modeling: A Multidisciplinary Journal, 8(3), 430-457. https://doi.org/10.1207/S15328007SEM0803_5

Etkin, A., Egner, T., \& Kalisch, R. (2011). Emotional processing in anterior cingulate and medial prefrontal cortex. Trends in Cognitive Sciences, 15(2), 85-93. https://doi.org/10.1016/j.tics.2010.11.004

Evans, G. W., Li, D., \& Whipple, S. S. (2013). Cumulative risk and child development. Psychological Bulletin, 139(6), 1342-1396. https://doi.org/10.1037/a0031808

Everaerd, D., Klumpers, F., Zwiers, M., Guadalupe, T., Franke, B., van Oostrom, I., Schene, A., Fernández, G., \& Tendolkar, I. (2016). Childhood abuse and deprivation are associated with distinct sex-dependent differences in brain morphology. Neuropsychopharmacology, 41(7), 1716-1723. https://doi.org/10.1038/npp.2015.344

Fonzo, G. A., Ramsawh, H. J., Flagan, T. M., Simmons, A. N., Sullivan, S. G., Allard, C. B., Paulus, M. P., \& Stein, M. B. (2016). Early life stress and the anxious brain: Evidence for a neural mechanism linking childhood emotional maltreatment to anxiety in adulthood. Psychological Medicine, 46(5), 1037-1054. https://doi.org/10.1017/S0033291715002603

Forehand, R., \& Jones, D. J. (2002). The stability of parenting: A longitudinal analysis of innercity african-american mothers. Journal of Child and Family Studies, 11(4), 455-467. 
Forman, S. D., Cohen, J. D., Fitzgerald, M., Eddy, W. F., Mintun, M. A., \& Noll, D. C. (1995). Improved Assessment of Significant Activation in Functional Magnetic Resonance Imaging (fMRI): Use of a Cluster-Size Threshold. Magnetic Resonance in Medicine, 33(5), 636-647. https://doi.org/10.1002/mrm.1910330508

Frick, P. J. (1991). The Alabama parenting questionnaire. Unpublished rating scale, University of Alabama.

Friston, K. J., Buechel, C., Fink, G. R., Morris, J., Rolls, E., \& Dolan, R. J. (1997). Psychophysiological and modulatory interactions in neuroimaging. Neuroimage, 6(3), $218-229$.

Fusar-Poli, P., Placentino, A., Carletti, F., Landi, P., \& Abbamonte, M. (2009). Functional atlas of emotional faces processing: A voxel-based meta-analysis of 105 functional magnetic resonance imaging studies. Journal of Psychiatry \& Neuroscience: JPN, 34(6), 418.

Fuster, J. M. (2001). The prefrontal cortex - an update: Time is of the essence. Neuron, 30(2), $319-333$.

Gard, A. M., McLoyd, V. C., Mitchell, C., \& Hyde, L. W. (2020). Evaluation of a longitudinal family stress model in a population-based cohort. Social Development, $n / a(\mathrm{n} / \mathrm{a})$. https://doi.org/10.1111/sode.12446

Gard, A. M., Waller, R., Shaw, D. S., Forbes, E. E., Hariri, A. R., \& Hyde, L. W. (2017). The Long Reach of Early Adversity: Parenting, Stress, and Neural Pathways to Antisocial Behavior in Adulthood. Biological Psychiatry: Cognitive Neuroscience and Neuroimaging, 2(7), 582-590. https://doi.org/10.1016/j.bpsc.2017.06.005

Gard, A. M., Waller, R., Swartz, J. R., Shaw, D. S., Forbes, E. E., \& Hyde, L. W. (2018). Amygdala functional connectivity during socioemotional processing prospectively 
predicts increases in internalizing symptoms in a sample of low-income, urban, young men. NeuroImage, 178, 562-573. https://doi.org/10.1016/j.neuroimage.2018.05.079

Gee, D. G., Gabard-Durnam, L., Telzer, E. H., Humphreys, K. L., Goff, B., Shapiro, M., Flannery, J., Lumian, D. S., Fareri, D. S., Caldera, C., \& Tottenham, N. (2014). Maternal Buffering of Human Amygdala-Prefrontal Circuitry During Childhood but Not During Adolescence. Psychological Science, 25(11), 2067-2078. https://doi.org/10.1177/0956797614550878

Gee, Dylan G. (2016). Sensitive Periods of Emotion Regulation: Influences of Parental Care on Frontoamygdala Circuitry and Plasticity. New Directions for Child and Adolescent Development, 2016(153), 87-110. https://doi.org/10.1002/cad.20166

Gee, Dylan G., Gabard-Durnam, L. J., Flannery, J., Goff, B., Humphreys, K. L., Telzer, E. H., Hare, T. A., Bookheimer, S. Y., \& Tottenham, N. (2013). Early developmental emergence of human amygdala-prefrontal connectivity after maternal deprivation. Proceedings of the National Academy of Sciences, 110(39), 15638-15643. https://doi.org/10.1073/pnas.1307893110

Gee, Dylan G., Humphreys, K. L., Flannery, J., Goff, B., Telzer, E. H., Shapiro, M., Hare, T. A., Bookheimer, S. Y., \& Tottenham, N. (2013). A developmental shift from positive to negative connectivity in human amygdala-prefrontal circuitry. Journal of Neuroscience, $33(10), 4584-4593$.

Ghashghaei, H. T., Hilgetag, C. C., \& Barbas, H. (2007). Sequence of information processing for emotions based on the anatomic dialogue between prefrontal cortex and amygdala. NeuroImage, 34(3), 905-923. https://doi.org/10.1016/j.neuroimage.2006.09.046 
Gianaros, P. J., Horenstein, J. A., Hariri, A. R., Sheu, L. K., Manuck, S. B., Matthews, K. A., \& Cohen, S. (2008). Potential neural embedding of parental social standing. Social Cognitive and Affective Neuroscience, 3(2), 91-96. https://doi.org/10.1093/scan/nsn003

Giedd, J. N., Blumenthal, J., Jeffries, N. O., Castellanos, F. X., Liu, H., Zijdenbos, A., Paus, T., Evans, A. C., \& Rapoport, J. L. (1999). Brain development during childhood and adolescence: A longitudinal MRI study. Nature Neuroscience, 2(10), 861-863. https://doi.org/10.1038/13158

Gilmore, J. H., Shi, F., Woolson, S. L., Knickmeyer, R. C., Short, S. J., Lin, W., Zhu, H., Hamer, R. M., Styner, M., \& Shen, D. (2012). Longitudinal Development of Cortical and Subcortical Gray Matter from Birth to 2 Years. Cerebral Cortex, 22(11), 2478-2485. https://doi.org/10.1093/cercor/bhr327

Glover, G. H., \& Law, C. S. (2001). Spiral-in/out BOLD fMRI for increased SNR and reduced susceptibility artifacts. Magnetic Resonance in Medicine, 46(3), 515-522. https://doi.org/10.1002/mrm.1222

Goetschius, L. G., Hein, T. C., Mattson, W. I., Lopez-Duran, N., Dotterer, H. L., Welsh, R. C., Mitchell, C., Hyde, L. W., \& Monk, C. S. (2019). Amygdala-prefrontal cortex white matter tracts are widespread, variable and implicated in amygdala modulation in adolescents. NeuroImage, 191, 278-291. https://doi.org/10.1016/j.neuroimage.2019.02.009

Gogtay, N., Giedd, J. N., Lusk, L., Hayashi, K. M., Greenstein, D., Vaituzis, A. C., Nugent, T. F., Herman, D. H., Clasen, L. S., Toga, A. W., Rapoport, J. L., \& Thompson, P. M. (2004). Dynamic mapping of human cortical development during childhood through 
early adulthood. Proceedings of the National Academy of Sciences, 101(21), 8174-8179. https://doi.org/10.1073/pnas.0402680101

Graham, A. M., Pfeifer, J. H., Fisher, P. A., Lin, W., Gao, W., \& Fair, D. A. (2015). The potential of infant fMRI research and the study of early life stress as a promising exemplar. Developmental Cognitive Neuroscience, 12, 12-39. https://doi.org/10.1016/j.dcn.2014.09.005

Green, J. G., McLaughlin, K. A., Berglund, P. A., Gruber, M. J., Sampson, N. A., Zaslavsky, A. M., \& Kessler, R. C. (2010). Childhood Adversities and Adult Psychiatric Disorders in the National Comorbidity Survey Replication I: Associations With First Onset of DSMIV Disorders. Archives of General Psychiatry, 67(2), 113-123. https://doi.org/10.1001/archgenpsychiatry.2009.186

Groenewold, N. A., Opmeer, E. M., de Jonge, P., Aleman, A., \& Costafreda, S. G. (2013). Emotional valence modulates brain functional abnormalities in depression: Evidence from a meta-analysis of fMRI studies. Neuroscience \& Biobehavioral Reviews, 37(2), 152-163. https://doi.org/10.1016/j.neubiorev.2012.11.015

Hariri, A. R. (2015). Looking inside the disordered brain (1st ed.). Sinauer Associates, Incorporated.

Harmer, C. J., Thilo, K. V., Rothwell, J. C., \& Goodwin, G. M. (2001). Transcranial magnetic stimulation of medial-frontal cortex impairs the processing of angry facial expressions. Nature Neuroscience, 4(1), 17-18. https://doi.org/10.1038/82854

Hein, T. C., Mattson, W. I., Dotterer, H. L., Mitchell, C., Lopez-Duran, N., Thomason, M. E., Peltier, S. J., Welsh, R. C., Hyde, L. W., \& Monk, C. S. (2018). Amygdala habituation 
and uncinate fasciculus connectivity in adolescence: A multi-modal approach.

NeuroImage, 183, 617-626. https://doi.org/10.1016/j.neuroimage.2018.08.058

Hein, T. C., \& Monk, C. S. (2017). Research Review: Neural response to threat in children, adolescents, and adults after child maltreatment-a quantitative meta-analysis. Journal of Child Psychology and Psychiatry, 58(3), 222-230.

Henckens, M. J. A. G., Klumpers, F., Everaerd, D., Kooijman, S. C., van Wingen, G. A., \& Fernández, G. (2016). Interindividual differences in stress sensitivity: Basal and stressinduced cortisol levels differentially predict neural vigilance processing under stress. Social Cognitive and Affective Neuroscience, 11(4), 663-673. https://doi.org/10.1093/scan/nsv149

Holz, N. E., Boecker-Schlier, R., Buchmann, A. F., Blomeyer, D., Jennen-Steinmetz, C., Baumeister, S., Plichta, M. M., Cattrell, A., Schumann, G., Esser, G., Schmidt, M., Buitelaar, J., Meyer-Lindenberg, A., Banaschewski, T., Brandeis, D., \& Laucht, M. (2017). Ventral striatum and amygdala activity as convergence sites for early adversity and conduct disorder. Social Cognitive and Affective Neuroscience, 12(2), 261-272. https://doi.org/10.1093/scan/nsw120

Hu, L., \& Bentler, P. M. (1999). Cutoff criteria for fit indexes in covariance structure analysis: Conventional criteria versus new alternatives. Structural Equation Modeling: A Multidisciplinary Journal, 6(1), 1-55.

Hyde, L. W., Shaw, D. S., \& Hariri, A. R. (2013). Understanding youth antisocial behavior using neuroscience through a developmental psychopathology lens: Review, integration, and directions for research. Developmental Review, 33(3), 168-223. https://doi.org/10.1016/j.dr.2013.06.001 
Javanbakht, A., King, A. P., Evans, G. W., Swain, J. E., Angstadt, M., Phan, K. L., \& Liberzon, I. (2015). Childhood Poverty Predicts Adult Amygdala and Frontal Activity and Connectivity in Response to Emotional Faces. Frontiers in Behavioral Neuroscience, 9. https://doi.org/10.3389/fnbeh.2015.00154

Jedd, K., Hunt, R. H., Cicchetti, D., Hunt, E., Cowell, R. A., Rogosch, F. A., Toth, S. L., \& Thomas, K. M. (2015). Long-term consequences of childhood maltreatment: Altered amygdala functional connectivity. Development and Psychopathology, 27(4pt2), 15771589. https://doi.org/10.1017/S0954579415000954

Jenkinson, M., Beckmann, C. F., Behrens, T. E. J., Woolrich, M. W., \& Smith, S. M. (2012). FSL. NeuroImage, 62(2), 782-790. https://doi.org/10.1016/j.neuroimage.2011.09.015

Kim, H. K., Pears, K. C., Fisher, P. A., Connelly, C. D., \& Landsverk, J. A. (2010). Trajectories of maternal harsh parenting in the first 3 years of life. Child Abuse \& Neglect, 34(12), 897-906. https://doi.org/10.1016/j.chiabu.2010.06.002

Kim, J., Lee, S. J., Taylor, C. A., \& Guterman, N. (2014). Dyadic Profiles of Parental Disciplinary Behavior and Links With Parenting Context. Child Maltreatment, 19(2), 7991. https://doi.org/10.1177/1077559514532009

Kim, M. J., Loucks, R. A., Palmer, A. L., Brown, A. C., Solomon, K. M., Marchante, A. N., \& Whalen, P. J. (2011). The structural and functional connectivity of the amygdala: From normal emotion to pathological anxiety. Behavioural Brain Research, 223(2), 403-410.

Kim, P., Evans, G. W., Angstadt, M., Ho, S. S., Sripada, C. S., Swain, J. E., Liberzon, I., \& Phan, K. L. (2013). Effects of childhood poverty and chronic stress on emotion regulatory brain function in adulthood. Proceedings of the National Academy of Sciences, 110(46), 18442-18447. https://doi.org/10.1073/pnas.1308240110 
Kubota, J. T., Banaji, M. R., \& Phelps, E. A. (2012). The neuroscience of race. Nature Neuroscience, 15(7), 940-948. https://doi.org/10.1038/nn.3136

Landry, S. H., Smith, K. E., Swank, P. R., \& Guttentag, C. (2008). A responsive parenting intervention: The optimal timing across early childhood for impacting maternal behaviors and child outcomes. Developmental Psychology, 44(5), 1335-1353. https://doi.org/10.1037/a0013030

LeDoux, J. E. (2000). Emotion circuits in the brain. Annual Review of Neuroscience, 23(1), 155184. https://doi.org/10.1146/annurev.neuro.23.1.155

Lee, D., Brooks-Gunn, J., McLanahan, S. S., Notterman, D., \& Garfinkel, I. (2013). The Great Recession, genetic sensitivity, and maternal harsh parenting. Proceedings of the National Academy of Sciences, 110(34), 13780-13784.

Lenroot, R. K., \& Giedd, J. N. (2006). Brain development in children and adolescents: Insights from anatomical magnetic resonance imaging. Neuroscience \& Biobehavioral Reviews, 30(6), 718-729. https://doi.org/10.1016/j.neubiorev.2006.06.001

Liberzon, I., Ma, S. T., Okada, G., Shaun Ho, S., Swain, J. E., \& Evans, G. W. (2015). Childhood poverty and recruitment of adult emotion regulatory neurocircuitry. Social Cognitive and Affective Neuroscience, nsv045. https://doi.org/10.1093/scan/nsv045

Lipscomb, S. T., Leve, L. D., Harold, G. T., Neiderhiser, J. M., Shaw, D. S., Ge, X., \& Reiss, D. (2011). Trajectories of Parenting and Child Negative Emotionality During Infancy and Toddlerhood: A Longitudinal Analysis: Parenting and Child Negative Emotionality. Child Development, 82(5), 1661-1675. https://doi.org/10.1111/j.1467-8624.2011.01639.x 
Loman, M. M., \& Gunnar, M. R. (2010). Early experience and the development of stress reactivity and regulation in children. Neuroscience \& Biobehavioral Reviews, 34(6), 867876. https://doi.org/10.1016/j.neubiorev.2009.05.007

Luby, J., Belden, A., Botteron, K., Marrus, N., Harms, M. P., Babb, C., Nishino, T., \& Barch, D. (2013). The Effects of Poverty on Childhood Brain Development: The Mediating Effect of Caregiving and Stressful Life Events. JAMA Pediatrics, 167(12), 1135. https://doi.org/10.1001/jamapediatrics.2013.3139

Lupien, S. J., McEwen, B. S., Gunnar, M. R., \& Heim, C. (2009). Effects of stress throughout the lifespan on the brain, behaviour and cognition. Nature Reviews Neuroscience, 10(6), 434-445. https://doi.org/10.1038/nrn2639

Maccoby, E. E., \& Martin, J. A. (1983). Socialization in the context of the family: Parent-child interaction. Handbook of Child Psychology: Formerly Carmichael's Manual of Child Psychology/Paul H. Mussen, Editor.

Maheu, F. S., Dozier, M., Guyer, A. E., Mandell, D., Peloso, E., Poeth, K., Jenness, J., Lau, J. Y. F., Ackerman, J. P., Pine, D. S., \& Ernst, M. (2010). A preliminary study of medial temporal lobe function in youths with a history of caregiver deprivation and emotional neglect. Cognitive, Affective, \& Behavioral Neuroscience, 10(1), 34-49. https://doi.org/10.3758/CABN.10.1.34

Maldjian, J. A., Laurienti, P. J., Kraft, R. A., \& Burdette, J. H. (2003). An automated method for neuroanatomic and cytoarchitectonic atlas-based interrogation of fMRI data sets. Neuroimage, 19(3), 1233-1239. https://doi.org/10.1016/S1053-8119(03)00169-1 
Marsh, A. A., \& Blair, R. J. R. (2008). Deficits in facial affect recognition among antisocial populations: A meta-analysis. Neuroscience \& Biobehavioral Reviews, 32(3), 454-465. https://doi.org/10.1016/j.neubiorev.2007.08.003

Marusak, H. A., Martin, K. R., Etkin, A., \& Thomason, M. E. (2015). Childhood trauma exposure disrupts the automatic regulation of emotional processing. Neuropsychopharmacology, 40(5), 1250-1258.

Masarik, A. S., \& Conger, R. D. (2017). Stress and child development: A review of the Family Stress Model. Current Opinion in Psychology, 13, 85-90. https://doi.org/10.1016/j.copsyc.2016.05.008

McCartney, K., Burchinal, M. R., \& Bub, K. L. (2006). Best practices in quantitative methods for developmentalists. Monographs of the Society for Research in Child Development, 71(3), 1-145. https://doi.org/10.1111/j.1540-5834.2006.07103001.x

McCrory, E. J., De Brito, S. A., Sebastian, C. L., Mechelli, A., Bird, G., Kelly, P. A., \& Viding, E. (2011). Heightened neural reactivity to threat in child victims of family violence. Current Biology, 21(23). https://doi.org/10.1016/ j.cub.2011 .10.015.

McEwen, B. S. (2012). Brain on stress: How the social environment gets under the skin. Proceedings of the National Academy of Sciences, 109(Supplement 2), 17180-17185.

McEwen, C. A., \& McEwen, B. S. (2017). Social Structure, Adversity, Toxic Stress, and Intergenerational Poverty: An Early Childhood Model. Annual Review of Sociology, 0. http://www.annualreviews.org/doi/abs/10.1146/annurev-soc-060116-053252

McLaren, D. G., Ries, M. L., Xu, G., \& Johnson, S. C. (2012). A generalized form of contextdependent psychophysiological interactions (gPPI): A comparison to standard approaches. Neuroimage, 61(4), 1277-1286. 
McLaughlin, K. A., Sheridan, M. A., \& Lambert, H. K. (2014). Childhood adversity and neural development: Deprivation and threat as distinct dimensions of early experience. Neuroscience \& Biobehavioral Reviews, 47, 578-591. https://doi.org/10.1016/j.neubiorev.2014.10.012

McLoyd, V. C. (1998). Socioeconomic disadvantage and child development. American Psychologist, 53(2), 185-204.

Menon, V. (2011). Large-scale brain networks and psychopathology: A unifying triple network model. Trends in Cognitive Sciences, 15(10), 483-506. https://doi.org/10.1016/j.tics.2011.08.003

Miller, J. G., Ho, T. C., Humphreys, K. L., King, L. S., Foland-Ross, L. C., Colich, N. L., Ordaz, S. J., Lin, J., \& Gotlib, I. H. (2020). Early Life Stress, Frontoamygdala Connectivity, and Biological Aging in Adolescence: A Longitudinal Investigation. Cerebral Cortex. https://doi.org/10.1093/cercor/bhaa057

Mochcovitch, M. D., da Rocha Freire, R. C., Garcia, R. F., \& Nardi, A. E. (2014). A systematic review of fMRI studies in generalized anxiety disorder: Evaluating its neural and cognitive basis. Journal of Affective Disorders, 167, 336-342. https://doi.org/10.1016/j.jad.2014.06.041

Monk, C. S. (2008). The development of emotion-related neural circuitry in health and psychopathology. Development and Psychopathology, 20(04), 1231. https://doi.org/10.1017/S095457940800059X

Moore, W. E., Pfeifer, J. H., Masten, C. L., Mazziotta, J. C., Iacoboni, M., \& Dapretto, M. (2012). Facing puberty: Associations between pubertal development and neural responses 
to affective facial displays. Social Cognitive and Affective Neuroscience, 7(1), 35-43. https://doi.org/10.1093/scan/nsr066

Morrison, F. J., Ponitz, C. C., \& McClelland, M. M. (2010). Self-regulation and academic achievement in the transition to school. In S. D. Calkins \& M. A. Bell (Eds.), Human brain development: Child development at the intersection of emotion and cognition. American Psychological Association.

Motzkin, J. C., Philippi, C. L., Wolf, R. C., Baskaya, M. K., \& Koenigs, M. (2015). Ventromedial prefrontal cortex is critical for the regulation of amygdala activity in humans. Biological Psychiatry, 77(3), 276-284.

Muthén, L. K., \& Muthén, B. O. (2006). Mplus Version 7 user's guide. Los Angeles, CA: Muthén \&Muthén.

Nagin, D. S., \& Odgers, C. L. (2010). Group-Based Trajectory Modeling in Clinical Research. Annual Review of Clinical Psychology, 6(1), 109-138. https://doi.org/10.1146/annurev.clinpsy.121208.131413

Oatley, K., \& Johnson-Laird, P. N. (1987). Towards a cognitive theory of emotions. Cognition and Emotion, 1(1), 29-50.

Ochsner, K. N., Silvers, J. A., \& Buhle, J. T. (2012). Functional imaging studies of emotion regulation: A synthetic review and evolving model of the cognitive control of emotion: Functional imaging studies of emotion regulation. Annals of the New York Academy of Sciences, 1251(1), E1-E24. https://doi.org/10.1111/j.1749-6632.2012.06751.x

Patterson, G. R. (1982). Coercive family process. Castalia Publishing Company.

Payne, C., Machado, C. J., Bliwise, N. G., \& Bachevalier, J. (2010). Maturation of the hippocampal formation and amygdala in Macaca mulatta: A volumetric magnetic 
resonance imaging study. Hippocampus, 20(8), 922-935.

https://doi.org/10.1002/hipo.20688

Pechtel, P., Lyons-Ruth, K., Anderson, C. M., \& Teicher, M. H. (2014). Sensitive periods of amygdala development: The role of maltreatment in preadolescence. NeuroImage, 97, 236-244. https://doi.org/10.1016/j.neuroimage.2014.04.025

Petersen, A. C., Crockett, L., Richards, M., \& Boxer, A. (1988). A self-report measure of pubertal status: Reliability, validity, and initial norms. Journal of Youth and Adolescence, 17(2), 117-133. https://doi.org/10.1007/BF01537962

Peverill, M., Sheridan, M. A., Busso, D. S., \& McLaughlin, K. A. (2019). Atypical PrefrontalAmygdala Circuitry Following Childhood Exposure to Abuse: Links With Adolescent Psychopathology. Child Maltreatment, 1077559519852676. https://doi.org/10.1177/1077559519852676

Pollak, S. D., \& Sinha, P. (2002). Effects of early experience on children's recognition of facial displays of emotion. Developmental Psychology, 38(5), 784-791. https://doi.org/10.1037//0012-1649.38.5.784

Pollak, S. D., \& Tolley-Schell, S. A. (2003). Selective attention to facial emotion in physically abused children. Journal of Abnormal Psychology, 112(3), 323-338. https://doi.org/10.1037/0021-843X.112.3.323

Pozzi, E., Simmons, J. G., Bousman, C. A., Vijayakumar, N., Bray, K. O., Dandash, O., Richmond, S., Schwartz, O., Seal, M., Sheeber, L., Yap, M. B. H., Allen, N. B., \& Whittle, S. L. (2019). The Influence of Maternal Parenting Style on the Neural Correlates of Emotion Processing in Children- ClinicalKey. Journal of the American Academy of Child \& Adolescent Psychiatry, 1:9. 
Price, J. L., \& Drevets, W. C. (2010). Neurocircuitry of mood disorders. Neuropsychopharmacology, 35(1), 192-216.

Puetz, V. B., Viding, E., Gerin, M. I., \& Pingault, J.-B. (2019). Investigating patterns of neural response associated with childhood abuse versus childhood neglect. Development and Psychopathology, 1-10. https:// doi.org/10.1017/S003329171900134X

Quirk, G. J., Garcia, R., \& González-Lima, F. (2006). Prefrontal Mechanisms in Extinction of Conditioned Fear. Biological Psychiatry, 60(4), 337-343. https://doi.org/10.1016/j.biopsych.2006.03.010

Reichman, N. E., Teitler, J. O., Garfinkel, I., \& McLanahan, S. S. (2001). Fragile families: Sample and design. Children and Youth Services Review, 23(4-5), 303-326.

Roy, A. K., Shehzad, Z., Margulies, D. S., Kelly, A. M. C., Uddin, L. Q., Gotimer, K., Biswal, B. B., Castellanos, F. X., \& Milham, M. P. (2009). Functional connectivity of the human amygdala using resting state fMRI. NeuroImage, 45(2), 614-626. https://doi.org/10.1016/j.neuroimage.2008.11.030

Sabatini, M. J., Ebert, P., Lewis, D. A., Levitt, P., Cameron, J. L., \& Mirnics, K. (2007). Amygdala Gene Expression Correlates of Social Behavior in Monkeys Experiencing Maternal Separation. Journal of Neuroscience, 27(12), 3295-3304. https://doi.org/10.1523/JNEUROSCI.4765-06.2007

Sameroff, A. J., Seifer, R., Barocas, R., Zax, M., \& Greenspan, S. (1987). Intelligence Quotient Scores of 4-Year-Old Children: Social-Environmental Risk Factors. Pediatrics, 79(3), $343-350$.

Shanahan, L., McHale, S. M., Osgood, D. W., \& Crouter, A. C. (2007). Conflict frequency with mothers and fathers from middle childhood to late adolescence: Within- and between- 
families comparisons. Developmental Psychology, 43(3), 539-550.

https://doi.org/10.1037/0012-1649.43.3.539

Shaw, D. S., \& Bell, R. Q. (1993). Developmental theories of parental contributors to antisocial behavior. Journal of Abnormal Child Psychology, 21(5), 493-518. https://doi.org/10.1007/BF00916316

Shaw, D. S., Gilliom, M., Ingoldsby, E. M., \& Nagin, D. S. (2003). Trajectories leading to school-age conduct problems. Developmental Psychology, 39(2), 189-200. https://doi.org/10.1037/0012-1649.39.2.189

Smith, S. M. (2002). Fast robust automated brain extraction. Human Brain Mapping, 17(3), 143155. https://doi.org/10.1002/hbm.10062

Sowell, E. R., Peterson, B. S., Thompson, P. M., Welcome, S. E., Henkenius, A. L., \& Toga, A. W. (2003). Mapping cortical change across the human life span. Nature Neuroscience, 6(3), 309-315. https://doi.org/10.1038/nn1008

Straus, M. A., Hamby, S. L., Finkelhor, D., Moore, D. W., \& Runyan, D. (1998). Identification of child maltreatment with the Parent-Child Conflict Tactics Scales: Development and psychometric data for a national sample of American parents. Child Abuse \& Neglect, 22(4), 249-270.

Suzuki, H., Luby, J. L., Botteron, K. N., Dietrich, R., McAvoy, M. P., \& Barch, D. M. (2014). Early life stress and trauma and enhanced limbic activation to emotionally valenced faces in depressed and healthy children. Journal of the American Academy of Child \& Adolescent Psychiatry, 53(7), 800-813.

Swartz, J. R., Carrasco, M., Wiggins, J. L., Thomason, M. E., \& Monk, C. S. (2014). Age-related changes in the structure and function of prefrontal cortex-amygdala circuitry in children 
and adolescents: A multi-modal imaging approach. NeuroImage, 86, 212-220. https://doi.org/10.1016/j.neuroimage.2013.08.018

Tamis-LeMonda, C. S., Briggs, R. D., McClowry, S. G., \& Snow, D. L. (2008). Challenges to the Study of African American Parenting: Conceptualization, Sampling, Research Approaches, Measurement, and Design. Parenting, 8(4), 319-358. https://doi.org/10.1080/15295190802612599

Taylor, S. E., Eisenberger, N. I., Saxbe, D., Lehman, B. J., \& Lieberman, M. D. (2006). Neural Responses to Emotional Stimuli Are Associated with Childhood Family Stress. Biological Psychiatry, 60(3), 296-301. https://doi.org/10.1016/j.biopsych.2005.09.027

Teicher, M. H., \& Samson, J. A. (2016). Annual Research Review: Enduring neurobiological effects of childhood abuse and neglect. Journal of Child Psychology and Psychiatry, 57(3), 241-266. https://doi.org/10.1111/jcpp.12507

Tottenham, N. (2015). Social scaffolding of human amygdala-mPFCcircuit development. Social Neuroscience, 10(5), 489-499.

Tottenham, N., Hare, T. A., Millner, A., Gilhooly, T., Zevin, J. D., \& Casey, B. J. (2011). Elevated amygdala response to faces following early deprivation: Neurodevelopment and adversity. Developmental Science, 14(2), 190-204. https://doi.org/10.1111/j.14677687.2010.00971.x

Tottenham, N., \& Sheridan, M. A. (2009). A review of adversity, the amygdala and the hippocampus: A consideration of developmental timing. Frontiers in Human Neuroscience, 3(68), 1-18. https://doi.org/10.3389/neuro.09.068.2009

Tottenham, N., Tanaka, J. W., Leon, A. C., McCarry, T., Nurse, M., Hare, T. A., Marcus, D. J., Westerlund, A., Casey, B., \& Nelson, C. (2009). The NimStim set of facial expressions: 
Judgments from untrained research participants. Psychiatry Research, 168(3), 242-249. https://doi.org/10.1016/j.psychres.2008.05.006

Trentacosta, C. J., Criss, M. M., Shaw, D. S., Lacourse, E., Hyde, L. W., \& Dishion, T. J. (2011). Antecedents and Outcomes of Joint Trajectories of Mother-Son Conflict and Warmth During Middle Childhood and Adolescence: Relationship Trajectories. Child Development, 82(5), 1676-1690. https://doi.org/10.1111/j.1467-8624.2011.01626.x van Harmelen, A.-L., van Tol, M.-J., Dalgleish, T., van der Wee, N. J. A., Veltman, D. J., Aleman, A., Spinhoven, P., Penninx, B. W. J. H., \& Elzinga, B. M. (2014). Hypoactive medial prefrontal cortex functioning in adults reporting childhood emotional maltreatment. Social Cognitive and Affective Neuroscience, 9(12), 2026-2033. https://doi.org/10.1093/scan/nsu008

Waller, R., Gard, A. M., Shaw, D. S., Forbes, E. E., Neumann, C. S., \& Hyde, L. W. (2018). Weakened Functional Connectivity Between the Amygdala and the Ventromedial Prefrontal Cortex Is Longitudinally Related to Psychopathic Traits in Low-Income Males During Early Adulthood. Clinical Psychological Science, 2167702618810231. https://doi.org/10.1177/2167702618810231

Whalen, P. J., \& Phelps, E. A. (2009). The human amygdala. Guilford Press. https://books.google.com/books?hl=en\&lr=\&id=275mEq72pkUC\&oi=fnd\&pg=PA3\&dq $=$ phelps+and+whalen\&ots=nbpSj5yHAM\&sig=s_CW_nOM58WzxSE1h97eBVVSwbc

Whittle, S., Simmons, J. G., Dennison, M., Vijayakumar, N., Schwartz, O., Yap, M. B. H., Sheeber, L., \& Allen, N. B. (2014). Positive parenting predicts the development of adolescent brain structure: A longitudinal study. Developmental Cognitive Neuroscience, 8, 7-17. https://doi.org/10.1016/j.den.2013.10.006 
Whittle, S., Vijayakumar, N., Dennison, M., Schwartz, O., Simmons, J. G., Sheeber, L., \& Allen, N. B. (2016). Observed Measures of Negative Parenting Predict Brain Development during Adolescence: E0147774. PLoS One; San Francisco, 11(1). http://dx.doi.org/10.1371/journal.pone.0147774

Whittle, S., Vijayakumar, N., Simmons, J. G., Dennison, M., Schwartz, O., Pantelis, C., Sheeber, L., Byrne, M. L., \& Allen, N. B. (2017). Role of Positive Parenting in the Association Between Neighborhood Social Disadvantage and Brain Development Across Adolescence. JAMA Psychiatry, 74(8), 824-832. https://doi.org/10.1001/jamapsychiatry.2017.1558

Whittle, S., Yap, M. B., Yücel, M., Fornito, A., Simmons, J. G., Barrett, A., Sheeber, L., \& Allen, N. B. (2008). Prefrontal and amygdala volumes are related to adolescents' affective behaviors during parent-adolescent interactions. Proceedings of the National Academy of Sciences, 105(9), 3652-3657.

Wu, M., Kujawa, A., Lu, L. H., Fitzgerald, D. A., Klumpp, H., Fitzgerald, K. D., Monk, C. S., \& Phan, K. L. (2016). Age-related changes in amygdala-frontal connectivity during emotional face processing from childhood into young adulthood. Human Brain Mapping, 37(5), 1684-1695. https://doi.org/10.1002/hbm.23129

Yang, Y., \& Raine, A. (2009). Prefrontal structural and functional brain imaging findings in antisocial, violent, and psychopathic individuals: A meta-analysis. Psychiatry Research: Neuroimaging, 174(2), 81-88. 